\title{
An Evidence-Based Review of OLZ/SAM for Treatment of Adults with Schizophrenia or Bipolar I Disorder
}

\author{
Leslie Citrome $\mathbb{1 D}^{\prime}$ \\ Christine Graham ${ }^{2}$ \\ Adam Simmons ${ }^{2}$ \\ Ying Jiang ${ }^{2}$ \\ Mark S Todtenkopf $\mathbb{1 D}^{2}$ \\ Bernard Silverman (D) ${ }^{2}$ \\ Lauren DiPetrillo ${ }^{2}$ \\ Hannah Cummings ${ }^{2}$ \\ Lei Sun $\mathbb{D}^{2}$ \\ David McDonnell ${ }^{3}$ \\ 'Department of Psychiatry and \\ Behavioral Sciences, New York Medical \\ College, Valhalla, NY, USA; ${ }^{2}$ Alkermes, \\ Inc., Waltham, MA, USA; ${ }^{3}$ Alkermes \\ Pharma Ireland Limited, Dublin, Ireland
}

Correspondence: Leslie Citrome

II Medical Park Drive, Suite 102,

Pomona, NY, 10970, USA

Tel + I-845-362-208I

Email citrome@cnsconsultant.com

\begin{abstract}
Olanzapine effectively treats schizophrenia and bipolar I disorder (BD-I); however, its use is limited by the risk of significant weight gain and metabolic effects. OLZ/SAM, a combination of olanzapine and samidorphan, was recently approved in the United States for the treatment of adults with schizophrenia or BD-I. OLZ/SAM provides the efficacy of olanzapine while mitigating olanzapine-associated weight gain through opioid-receptor blockade. Here, we summarize OLZ/SAM clinical data characterizing pharmacokinetics, antipsychotic efficacy, weight mitigation efficacy, safety, and long-term treatment effects. In an acute exacerbation of schizophrenia, OLZ/SAM and olanzapine provided similar symptom improvements versus placebo at week 4. In stable outpatients with schizophrenia, OLZ/SAM treatment resulted in significantly less weight gain, reducing the risk for clinically significant weight gain and waist circumference increases of $\geq 5 \mathrm{~cm}$ by half, compared with olanzapine at week 24 . Based on openlabel extension studies, OLZ/SAM is safe and well tolerated for up to 3.5 years of treatment, while maintaining schizophrenia symptom control and stabilizing weight. The olanzapine component of OLZ/SAM was bioequivalent to branded olanzapine (Zyprexa); adjunctive OLZ/SAM had no clinically significant effects on lithium or valproate pharmacokinetics. Additionally, OLZ/SAM had no clinically relevant effect on electrocardiogram parameters in a dedicated thorough QT study. Overall, safety and tolerability findings from clinical studies with OLZ/SAM indicate a similar safety profile to that of olanzapine, with the exception of less weight gain. As OLZ/SAM contains the opioid antagonist samidorphan, it is contraindicated in patients using opioids and in those undergoing acute opioid withdrawal. Clinical trial results from more than 1600 subjects support the use of OLZ/SAM as a new treatment option for patients with schizophrenia or BD-I.
\end{abstract}

Keywords: antipsychotic agents, clinical efficacy, olanzapine, opioid antagonists, safety, weight gain

\section{Plain Language Summary}

Antipsychotic choice for individuals with schizophrenia or bipolar I disorder (BD-I) requires balancing efficacy with tolerability. For example, while olanzapine is highly efficacious, it is associated with weight gain and/or changes in how the body regulates glucose and lipids. Since the body's natural opioid system is involved in regulating weight and metabolism, combining samidorphan with olanzapine is a potential strategy to address olanzapine-associated weight and metabolic side effects. We summarize clinical data for OLZ/SAM, a combination of olanzapine and the opioid receptor-blocking compound samidorphan, recently approved in the United States for the treatment of adults with schizophrenia or BD-I. In pharmacokinetic studies, plasma concentrations of olanzapine were similar when 
administered as OLZ/SAM or as the branded product, Zyprexa, with dose-proportional increases in concentration with increasing doses. Adjunctive OLZ/SAM did not affect lithium or valproate pharmacokinetics. Samidorphan's pharmacokinetic profile supports once-daily dosing in combination with olanzapine as OLZ/SAM. In clinical studies, OLZ/SAM provided similar antipsychotic efficacy as olanzapine in patients with schizophrenia, with sustained symptom control during long-term treatment. OLZ/SAM treatment resulted in significantly less weight gain versus olanzapine; weight remained stable with long-term treatment. The safety profile of OLZ/SAM was generally consistent with that of olanzapine, except for less weight gain. Owing to samidorphan's opioid antagonist effects, OLZ/SAM is contraindicated in patients using opioids or undergoing acute opioid withdrawal. Lastly, because antipsychotic-associated weight gain is independent of disease state, OLZ/SAM provides a new treatment option for patients with either schizophrenia or BD-I that balances efficacy with a reduced risk of weight gain.

\section{Introduction}

Schizophrenia and bipolar I disorder (BD-I) are chronic, complex psychiatric illnesses associated with substantial functional impairment and disability, ${ }^{1-3}$ high rates of comorbid conditions, ${ }^{4,5}$ and a high risk of suicide. ${ }^{6,7}$ Both are associated with lower life expectancy, attributable in part to causes such as suicide, but also to higher rates of cardiovascular comorbidities. ${ }^{5,8,9}$ While antipsychotics are the cornerstone of treatment in schizophrenia, and secondgeneration antipsychotics are commonly prescribed in the treatment of BD-I either as monotherapy or in combination with mood stabilizers, ${ }^{10,11}$ they are often accompanied by adverse side effects ${ }^{12}$ that may contribute to suboptimal adherence and/or treatment discontinuation or to emergent cardiometabolic comorbidities. ${ }^{13,14}$ Despite a number of available antipsychotics, there remains a need for effective therapies with acceptable tolerability profiles that support long-term use. ${ }^{15-17}$

Based on data from clinical trials, ${ }^{18,19}$ real-world settings, ${ }^{20-22}$ meta-analyses, ${ }^{23,24}$ and pooled analyses, ${ }^{25}$ olanzapine is one of the most effective antipsychotics for the treatment of schizophrenia. ${ }^{26,27}$ Olanzapine also effectively treats manic or mixed episodes associated with BD-I and reduces relapse risk during maintenance treatment. ${ }^{28-30}$ While olanzapine's efficacy is well established, ${ }^{18,23,28,29,31}$ the clinical utility of olanzapine has been hampered by the risk of substantial weight gain and metabolic effects, ${ }^{32-38}$ such as elevations in blood glucose and lipid concentrations, waist circumference increases, and development of metabolic syndrome. ${ }^{36,37,39}$ Approximately $80 \%$ of patients gain at least $5 \mathrm{~kg}$ with long-term olanzapine treatment, ${ }^{40}$ and this weight gain can continue over several months or even years. ${ }^{40-43}$ In studies lasting at least 48 weeks, $64 \%$ of patients taking olanzapine gained at least $7 \%$ of their baseline body weight, and $12 \%$ gained at least $25 \%$ of their baseline body weight. ${ }^{40}$ Increases in waist circumference, reflecting central fat accumulation, are associated with higher cardiometabolic and mortality risks. ${ }^{44,45}$ Consistent with weight gain and/or increases in waist circumference, long-term olanzapine use increases the risk of developing diabetes or hyperlipidemia, ${ }^{46-49}$ as well as cardiovascular disease. ${ }^{45}$

The endogenous opioid receptor system is involved in the regulation of weight gain and metabolism. ${ }^{50-55}$ Opioid receptors exist in both the central nervous system and in the periphery (eg, the pancreas, muscle, and liver), ${ }^{56-58}$ making the opioid system a potential therapeutic target for addressing antipsychotic-associated weight gain. A combination of olanzapine and the opioid receptor antagonist samidorphan (OLZ/SAM; Lybalvi, Alkermes, Inc.) was recently approved by the US Food and Drug Administration (FDA) for the treatment of adults with schizophrenia or BD-I. ${ }^{59}$ OLZ/SAM provides the antipsychotic efficacy of olanzapine, but with less weight gain. $^{60-62}$ OLZ/SAM is being developed to include 5-, 10-, 15-, or 20-mg doses of olanzapine (similar to dose ranges approved for adults with schizophrenia or BD-I $)^{40}$ with a fixed 10-mg dose of samidorphan in a single tablet.

\section{Overview of Clinical Trials}

The effects of OLZ/SAM on weight gain and body composition have been previously characterized in preclinical studies in rats and nonhuman primates. ${ }^{63}$ In this narrative review, we summarize the clinical data for OLZ/SAM and describe its overall efficacy and safety profile.

The clinical development program of OLZ/SAM includes 18 studies: 10 Phase $1,{ }^{64-72}$ two Phase $2,^{60,73}$ three randomized, double-blind Phase 3 (Study A307; NCT03187769), ${ }^{61,62}$ and three open-label, long-term, phase 3 safety extension studies (Study A308; NCT03201757) ${ }^{74,75}$ (Supplemental Table 1). These studies provided information on the pharmacokinetics, ${ }^{64-69}$ safety, ${ }^{70,74,75}$ and efficacy (both antipsychotic efficacy as well as mitigation of weight gain relative to olanzapine [ie, weight efficacy] $)^{60-62}$ of OLZ/SAM. 


\section{Pharmacology and Mode of Action of Samidorphan}

The body's endogenous opioid system is involved in the regulation of weight and metabolism. ${ }^{50-55}$ Samidorphan is an opioid receptor antagonist that binds to and blocks opioid receptors. ${ }^{76,77}$ The exact mechanism(s) by which samidorphan mitigates olanzapine-associated weight gain is unknown. Samidorphan has unique binding properties, functional activity, and pharmacokinetic attributes that differentiate it from other opioid antagonists. ${ }^{77-79}$ It is thought that in the central nervous system, opioid receptor blockade may reduce the rewarding effects of stimuli in systems where aberrant opioid signaling may contribute to motivational dysregulation, such as in behavioral addiction (eg, binge-eating or gambling). ${ }^{80-82}$ In the periphery, blockade or genetic ablation of opioid receptors alters fat accumulation and glucose utilization, as well as glucose homeostasis. ${ }^{63,83-85}$ Therefore, the weight-mitigating properties of samidorphan in combination with olanzapine may be mediated through opioid receptor blockade in both central and peripheral compartments.

\section{Pharmacokinetics and Pharmacodynamics}

The pharmacokinetics of oral olanzapine and samidorphan have been extensively characterized alone and in combination. ${ }^{64-67,71,79,86,87}$ Samidorphan has an oral bioavailability of $69 \%$ and a half-life of approximately 7 to 10 hours, ${ }^{79,87}$ making it suitable for once-daily dosing in combination with olanzapine. Combining olanzapine with samidorphan did not affect the pharmacokinetics of either drug. ${ }^{66,71}$ After once-daily dosing of OLZ/SAM at doses of $10 / 10 \mathrm{mg}$ to $20 / 10 \mathrm{mg}$, steady-state olanzapine exposures increased dose proportionally. ${ }^{66}$ In addition, consuming a high-fat, high-calorie meal prior to taking OLZ/SAM had no clinically relevant effects on the pharmacokinetics of olanzapine or samidorphan; therefore, OLZ/SAM can be taken with or without food. ${ }^{67}$

The olanzapine component of OLZ/SAM was bioequivalent to branded olanzapine oral tablets (Zyprexa, Eli Lilly and Company; Supplemental Figure 1A) ${ }^{64}$ Furthermore, coadministration of OLZ/SAM with lithium or valproate had no clinically significant effect on systemic exposures of lithium or valproate (Supplemental Figures $\underline{1 \mathrm{~B}}$ and $\underline{\mathrm{C}}){ }^{68}$

Drug-drug interactions known to be important for olanzapine should be considered important for OLZ/SAM as well. ${ }^{40}$ In addition, coadministration of OLZ/SAM with rifampin, a strong inducer of cytochrome P450 [CYP]3A4 and an inducer of uridine 5'-diphospho-glucuronosyltransferase [UGT] enzymes, decreased the total systemic exposure of olanzapine and samidorphan by $48 \%$ and $73 \%$, respectively. ${ }^{65}$ This effect is consistent with the known metabolic pathways for olanzapine (primarily via UGT-mediated direct glucuronidation and CYP-mediated oxidation) ${ }^{88,89}$ and for samidorphan (predominately mediated by CYP3A4). ${ }^{79}$ Therefore, concomitant use of OLZ/SAM with strong CYP3A4 inducers, such as rifampin, is not recommended. ${ }^{59}$

Subjects with severe renal impairment had up to a 2.3-fold increase in the total systemic exposure of olanzapine and samidorphan, while subjects with moderate hepatic impairment had up to 1.7 -fold increases in total systemic exposure of olanzapine and samidorphan. ${ }^{69}$ No dose adjustment is needed for OLZ/SAM in patients with hepatic or renal impairment, but OLZ/SAM is not recommended for patients with end-stage renal disease. ${ }^{59}$

Based on a thorough QT study conducted in patients with schizophrenia, OLZ/SAM, at doses up to a supratherapeutic dose of $30 / 30 \mathrm{mg}$, had no clinically relevant effect on electrocardiogram parameters, including QT interval. ${ }^{70}$ Because no formal QT study had been conducted previously with olanzapine, this study fills an important information gap and provides further clinical context for the safety of OLZ/SAM treatment. Supplemental Table 1 summarizes these data, as well as data from other pharmacokinetic and pharmacodynamic studies.

The abuse potential of samidorphan has been assessed ${ }^{90}$ in a study with naltrexone, an opioid antagonist with no abuse potential, ${ }^{91}$ serving as a negative control. Samidorphan's score on a drug-liking visual analog scale was similar to both placebo and naltrexone, indicating that samidorphan has no abuse potential. ${ }^{90}$ Furthermore, at doses of $10 \mathrm{mg}$ and $30 \mathrm{mg}$, samidorphan had significantly lower drug-liking scores compared with those of the positive controls, oxycontin and pentazocine, which are scheduled drugs with known abuse potential.

\section{Efficacy and Safety Overview}

The antipsychotic efficacy of OLZ/SAM was primarily evaluated in a pivotal phase 3 study in patients with an acute exacerbation of schizophrenia, ${ }^{61}$ while weight efficacy was primarily evaluated in a pivotal phase 3 study of stable 
outpatients with schizophrenia. ${ }^{62}$ Additional studies support the antipsychotic ${ }^{60,62}$ and weight mitigation ${ }^{60}$ efficacy of OLZ/SAM. The durability of antipsychotic and weight mitigation effects, as well as long-term effects on metabolic parameters, were derived from two 52-week, open-label, extension studies. ${ }^{74,75}$ These findings are summarized below; additional detailed descriptions can be found in Tables 1 and 2 .

Table 3 presents a summary of adverse events (AEs) and other key safety observations. In addition to collecting safety information from different populations of patients with schizophrenia (ie, acutely ill inpatients and stable outpatients), OLZ/SAM safety information was also derived from a study in patients with schizophrenia and comorbid alcohol use disorder. $^{73}$ In general, the AE profile for OLZ/SAM was similar to that of olanzapine, except for less weight gain. Because samidorphan is an opioid antagonist, concomitant use of opioids was exclusionary in the OLZ/SAM clinical trials, and OLZ/SAM is contraindicated in patients using opioids and in those undergoing acute opioid withdrawal. ${ }^{59}$

\section{Specific Study Results Related to Antipsychotic Effects}

The phase 3 ENLIGHTEN-1 study evaluated the antipsychotic efficacy of OLZ/SAM in patients experiencing an acute exacerbation of schizophrenia requiring inpatient treatment. Treatment with OLZ/SAM resulted in significant improvements in symptoms compared with placebo at week 4, as measured by changes in Positive and Negative Syndrome Scale (PANSS) total scores from baseline ${ }^{61}$ (Figure 1A, Table 2). Improvement in PANSS scores with OLZ/SAM relative to placebo was similar to that observed with olanzapine; Figure 1A, Table 2). Antipsychotic efficacy of OLZ/SAM relative to placebo was also supported by improvements in Clinical Global Impression-Severity (CGI-S) scores ${ }^{61}$ (Table 2). The inclusion of samidorphan in OLZ/SAM did not negatively impact the antipsychotic efficacy of olanzapine. ${ }^{59}$

The efficacy of OLZ/SAM in controlling symptoms of schizophrenia was further supported by findings from ENLIGHTEN-2, ${ }^{62}$ a pivotal study assessing weight gain as the primary endpoint. In that study, 24 weeks of treatment with either OLZ/SAM or olanzapine resulted in similar improvements in PANSS total and CGI-S scores (Figure 1B; Table 2). Details and key findings on these and other studies assessing antipsychotic effects of OLZ/SAM are provided in Table 2 and in Figure 1B and C. The long-term effects of OLZ/SAM are summarized below.

\section{Specific Study Results Related to Effects on Weight, Waist Circumference, and Metabolic Parameters}

The 24-week phase 3 ENLIGHTEN-2 study primarily assessed the weight profile of OLZ/SAM versus olanzapine in stable outpatients with schizophrenia (Table 1). ${ }^{62}$ Patients treated with OLZ/SAM gained significantly less weight than those treated with olanzapine (Table 2). ${ }^{62}$ Figure 2A depicts the mean percent body weight changes in this study, which were similar to the findings observed in a phase 2 dose-finding study (Figure 2B). ${ }^{60}$ In the 24-week study, the least squares (LS) mean percent weight change from baseline to the end of treatment was $4.2 \%$ with OLZ/SAM versus $6.6 \%$ with olanzapine, yielding an LS mean difference of $-2.4 \% .{ }^{62}$ In the phase 2 study, the LS mean percent change from baseline in weight at week 12 was $2.6 \%$ with OLZ/SAM versus $4.1 \%$ with olanzapine, yielding an LS mean difference between groups of $-1.5 \%{ }^{60}$ In both studies, patients treated with olanzapine and OLZ/SAM had similar weight gain for the first 4 to 6 weeks. With OLZ/SAM, weight gain stabilized thereafter, whereas patients who received olanzapine continued to gain weight throughout the remainder of the treatment period. ${ }^{60,62}$ In ENLIGHTEN-2, this resulted in an alteration of the weight gain trajectory (eg, the distribution curve of weight gain was shifted for OLZ/SAM compared with olanzapine, indicating that fewer patients gained weight across a wide range of percent weight gain cutoffs; Figure 2C).

In addition to assessing differences in mean percent weight gain, the ENLIGHTEN-2 study assessed the proportion of patients gaining at least $10 \%$ of their body weight as a coprimary endpoint. The risk of gaining $10 \%$ or more of body weight from baseline was reduced by $50 \%$ with OLZ/SAM compared with olanzapine. In psychiatric practice, a weight gain of 7\% or more is considered to be clinically significant. ${ }^{92,93}$ As with the $10 \%$ weight gain threshold, the odds of gaining $7 \%$ body weight or more from baseline at week 24 was also reduced by $50 \%$ for OLZ/SAM compared with olanzapine (Table 2; Figure 2C). Based on a number needed to treat (NNT) analysis of the proportion of patients with clinically significant weight gain at week 24, the NNT for OLZ/SAM versus olanzapine was 7 and 8 for the $\geq 7 \%$ and $\geq 10 \%$ weight gain thresholds, respectively (Table 2). Generally, NNTs less than 10 denote a clinically meaningful effect size, and the lower the NNT value, the better the treatment response. ${ }^{94,95}$ 


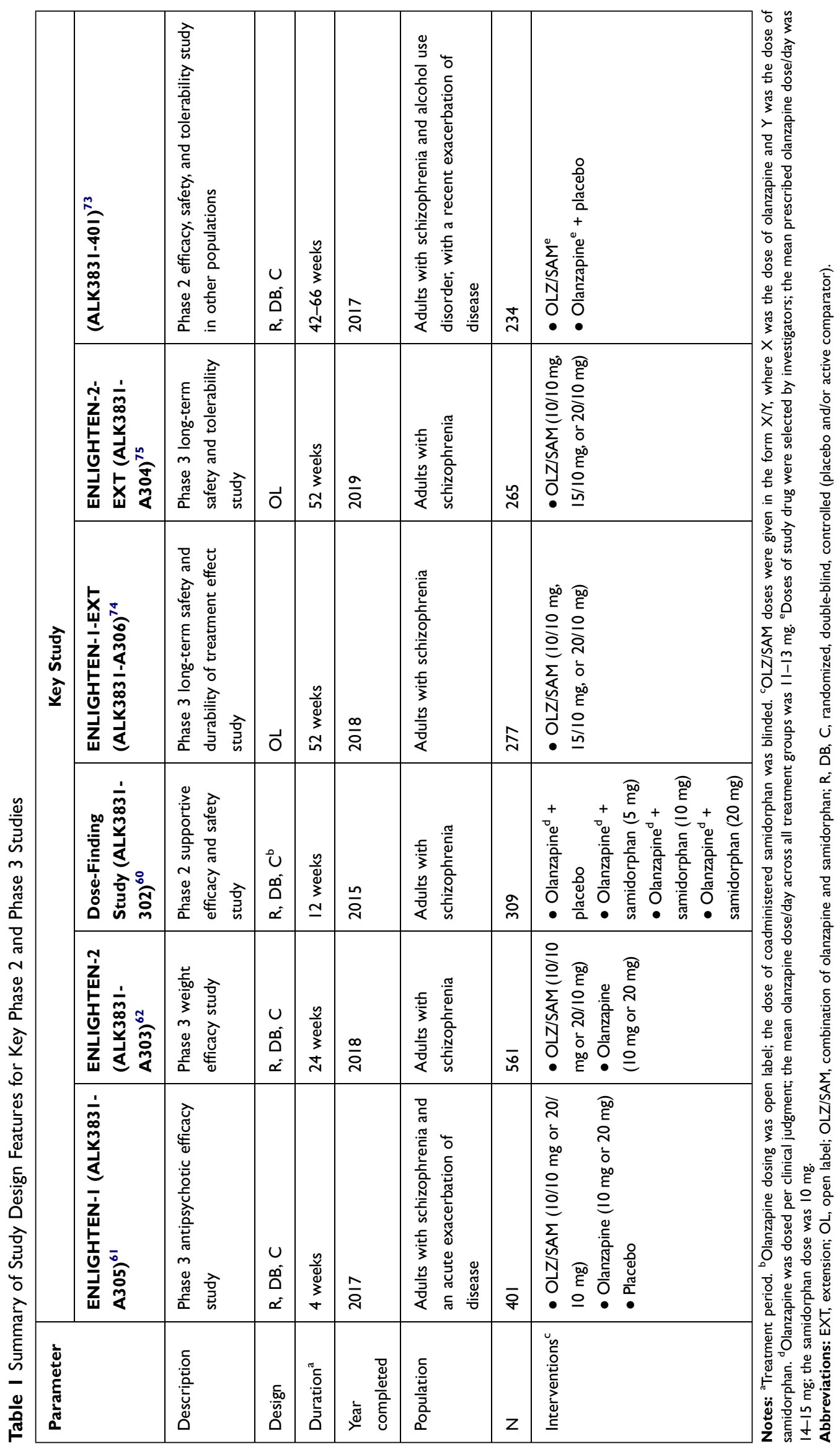


Table 2 Summary of Study Findings from Key Phase 2 and Phase 3 Studies

\begin{tabular}{|c|c|}
\hline Study & Key Findings \\
\hline $\begin{array}{l}\text { Antipsychotic efficacy study } \\
\text { ENLIGHTEN-I (ALK383I-A305) }\end{array}$ & $\begin{array}{l}\text { - Treatment with OLZ/SAM resulted in significant improvement in PANSS total score }\left(I^{\circ} \mathrm{EP}\right) \\
\text { at week } 4 \text { vs placebo (LS mean: }-23.9 \text { vs }-17.5 ; P<0.00 \mathrm{I}) \\
\text { - Magnitude of PANSS changes observed with OLZ/SAM was similar to that observed with } \\
\text { olanzapine vs placebo at week } 4 \text { (LS mean: }-22.8 \text { vs }-17.5, P=0.004) \\
\text { - LS mean change in PANSS total score from baseline to week } 4 \text { was }-6.4(P<0.00 I) \text { with } \\
\text { OLZ/SAM and }-5.3(P=0.004) \text { with olanzapine } \\
\left.\text { - LS mean CGI-S scores (key } 2^{\circ} \mathrm{EP}\right) \text { at week } 4 \text { were }-1.2 I,-1.27 \text {, and }-0.84 \text { in the OLZ/SAM, } \\
\text { olanzapine, and placebo groups, respectively; OLZ/SAM and olanzapine had significant } \\
\text { improvements vs placebo }(P=0.002 \text { and } P<0.00 I \text {, respectively) } \\
\text { - Key safety findings are presented in Table } 3\end{array}$ \\
\hline $\begin{array}{l}\text { Weight efficacy study } \\
\text { ENLIGHTEN-2 (ALK383I-A303) }{ }^{62}\end{array}$ & 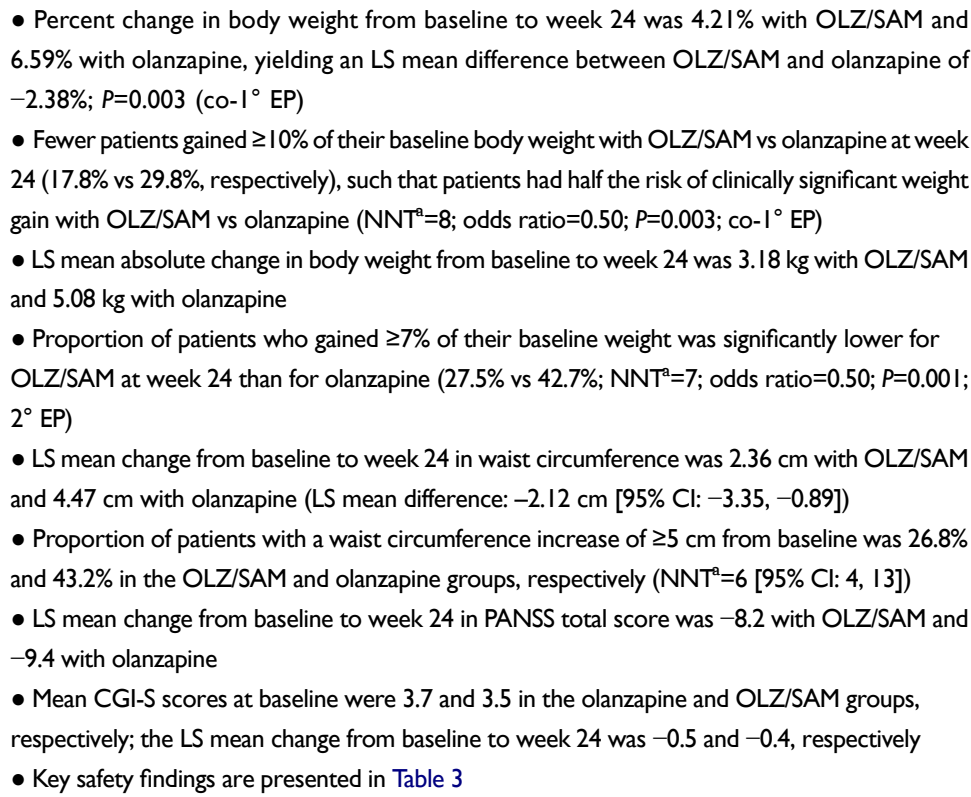 \\
\hline $\begin{array}{l}\text { Phase } 2 \text { supportive efficacy and safety study } \\
\text { dose-finding study (ALK383I-302) }\end{array}$ & $\begin{array}{l}\text { - PANSS score changes were similar between groups: LS mean }(95 \% \mathrm{Cl}) \text { change from } \\
\text { baseline to week } 12 \text { in PANSS total score was }-2.2(-3.2,-1.3) \text { with olanzapine }+ \\
\text { samidorphan and }-2.9(-4.5,-1.3) \text { with olanzapine }+ \text { placebo }\left(1^{\circ} \mathrm{EP}\right) \\
\text { - Weight change with olanzapine }+ \text { samidorphan was lower at week } 12 \text { than with olanzapine + } \\
\text { placebo (mean absolute change was } 1.9 \mathrm{~kg} \text { vs } 2.9 \mathrm{~kg} \text {, respectively; } \text { LS mean difference: }-1.0 \text { [ } 95 \% \\
\mathrm{Cl}:-1.8,-0.2]) \\
\text { - Key safety findings are presented in Table } 3\end{array}$ \\
\hline $\begin{array}{l}\text { Long-term safety and durability of treatment effect study (I) } \\
\text { ENLIGHTEN-I-EXT (ALK383I-A306) }\end{array}$ & $\begin{array}{l}\text { - Assessment of safety and tolerability were primary study objectives } \\
\text { - AEs occurred in } 136 \text { ( } 49.1 \%) \text { patients; most were mild or moderate in severity } \\
\text { - The most common AEs were increased weight }(13.4 \%) \text {, somnolence }(8.3 \%) \text {, } \\
\text { nasopharyngitis }(4.0 \%) \text {, and headache }(4.0 \%) \\
\text { - Mean change from baseline to week } 52 \text { in body weight was } 1.86 \mathrm{~kg} \\
\text { - Parkinsonism, akathisia, and dyskinesia occurred in } 7 \%, 5 \% \text {, and } 3 \% \text { of patients, respectively } \\
\text { - During the treatment and follow-up periods, } 5(1.8 \%) \text { patients had suicidal ideation, suicidal } \\
\text { behavior, or intentional overdose identified } \\
\text { - Mean PANSS total score was } 78.9 \text { ( } n=248) \text { at study start } \\
\text { - Schizophrenia symptoms improved over } 52 \text { weeks of treatment, with PANSS total scores } \\
\text { decreasing by } 16.2 \text { points at week } 52 \\
\text { - CGI-S scores also improved over the } 52 \text {-week treatment period; mean CGI-S baseline score } \\
\text { was } 3.9 \text { ( } n=248) \text { and decreased by } 0.9 \text { points at week } 52 \text { ( } n=182 \text { patients with available } \\
\text { assessments) }\end{array}$ \\
\hline
\end{tabular}

(Continued) 
Table 2 (Continued).

\begin{tabular}{|c|c|}
\hline Study & Key Findings \\
\hline $\begin{array}{l}\text { Long-term safety and durability of treatment effect study (2) } \\
\text { ENLIGHTEN-2-EXT (ALK383I-A304) }\end{array}$ & $\begin{array}{l}\text { - Assessment of safety and tolerability were primary study objectives } \\
\text { - In total, } 60.8 \% \text { of patients experienced any AE; the majority were of mild or moderate } \\
\text { severity } \\
\text { - AEs occurring in } \geq 5 \% \text { patients: weight decreased ( } 8.7 \% \text { ), extra dose administered ( } 7.9 \% \text { ), } \\
\text { headache }(6.8 \%) \text {, and weight increased }(6.0 \%) \\
\text { - Mean change from baseline to week } 52 \text { in body weight was }-0.03 \mathrm{~kg} \\
\text { - Mean change from baseline to week } 52 \text { in waist circumference was }-0.35 \mathrm{~cm} \\
\text { - Rates of parkinsonism, akathisia, and dyskinesia were } 4 \%, 2 \% \text {, and } 2 \% \text {, respectively } \\
\text { - } 6.8 \% \text { of patients experienced suicidal ideation and } 0.4 \% \text { experienced the suicidal behavior } \\
\text { of preparatory acts or behavior } \\
\text { - These outpatients had a mean baseline PANSS total score of } 59.0 \text { ( } n=265 \text { ) } \\
\text { - Mean PANSS total score remained stable ( } 58.3 \text { at week } 52 \text { in } 168 \text { patients with available } \\
\text { assessments) } \\
\text { - CGI-S scores changed little over the course of ENLIGHTEN-2-EXT (mean score at } \\
\text { baseline: } 3.1 \text {; mean score at week } 52: 3.0 \text { ) }\end{array}$ \\
\hline $\begin{array}{l}\text { Other populations, treatment effects in schizophrenia and } \\
\text { comorbid alcohol use disorder (ALK383I-40I })^{73}\end{array}$ & $\begin{array}{l}\text { - The difference between OLZ/SAM and olanzapine on time to first event of exacerbation } \\
\text { of disease symptoms was not significant ( } I^{\circ} \mathrm{EP} \text {; hazard ratio: } 0.9 \mathrm{I} ; 95 \% \mathrm{Cl}: 0.53,1.56 \text {; } \\
P=0.746 \text { ) } \\
\text { - There were no between-group differences in alcohol use behavior, as measured by } \\
\text { changes in WHO drinking risk level, number of heavy drinking days, or desire for alcohol } \\
\text { - Similar improvements in PANSS total scores were observed with either treatment at } \\
\text { week } 63 \text { relative to randomization (change of }-5.4 \text { for OLZ/SAM and of }-3.4 \text { for } \\
\text { olanzapine) } \\
\text { - Overall, } 57.1 \% \text { of patients treated with OLZ/SAM and } 59.0 \% \text { of patients treated with } \\
\text { olanzapine reported any AEs } \\
\text { - The most commonly reported AEs (occurring in } \geq 3 \% \text { of patients in both groups) were } \\
\text { weight gain, nasopharyngitis, and exacerbation of schizophrenia symptoms } \\
\text { - Key safety findings are presented in Table } 3\end{array}$ \\
\hline
\end{tabular}

Notes: ${ }^{2} \mathrm{NNT}$ values were calculated from the proportion of patients using a logistic regression model to adjust for covariates at baseline. Thus, the NNT and $95 \% \mathrm{Cl}$ values described here can differ from raw NNT estimates calculated from the actual rates without adjustment for covariates. In a study of human abuse potential, samidorphan had no abuse potential and had a profile consistent with naltrexone, a negative control in the study. ${ }^{90}$

Abbreviations: $\mathrm{I}^{\circ} \mathrm{EP}$, prespecified primary endpoint; $2^{\circ} \mathrm{EP}$, prespecified secondary endpoint; AE, adverse event; CGI-S, Clinical Global Impression-Severity; CI, confidence interval; EXT, extension; LS, least squares; NNT, number needed to treat; OLZ/SAM, combination of olanzapine and samidorphan; PANSS, Positive and Negative Syndrome Scale; WHO, World Health Organization.

OLZ/SAM was also associated with smaller increases in waist circumference compared with olanzapine (Table 2; Figure 3A), ${ }^{62}$ which occurred as early as week 1 . As with the distribution curve for weight gain, the distribution curve for waist circumference increases was also shifted. Fewer patients had waist circumference increases across a range of cutoff values in comparison to olanzapine. The risk of experiencing a 5 -cm increase in waist circumference was 50\% lower for patients treated with OLZ/SAM versus olanzapine (Table 2; Figure 3B). This is clinically significant, as a $5-\mathrm{cm}$ or greater increase in waist circumference is associated with an increased risk of all-cause mortality and cardiovascular disease. ${ }^{44}$ The NNT for the proportion of patients with a waist circumference increase of $\geq 5 \mathrm{~cm}$ in the OLZ/SAM group versus the olanzapine group was 6 (Table 2).
Changes in metabolic laboratory parameters in patients treated with olanzapine or OLZ/SAM in ENLIGHTEN-2 were generally small and were similar between groups (Figure 4A and B). In addition, there were little differences between the two treatment groups in metabolic parameter changes considered to be of potential clinical significance, based on commonly used thresholds (Supplemental Table 2). In the context of metabolic laboratory parameters, sustained shifts are more clinically relevant than single excursions resulting from visit-to-visit variability or inconsistencies in fasting status. Across the fasting lipid and glycemic parameters, the incidence of sustained shifts was substantially lower than the incidence of anytime shifts and was similar for both groups (Supplemental Table 2). 


\begin{tabular}{|c|c|c|c|c|c|c|c|c|c|}
\hline & 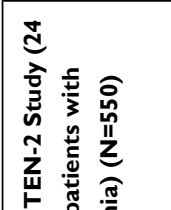 & 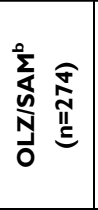 & 0 & $\begin{array}{l}\hat{0} \\
\stackrel{0}{0} \\
\underline{0}\end{array}$ & 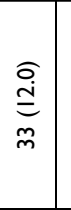 & 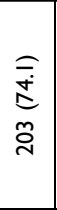 & 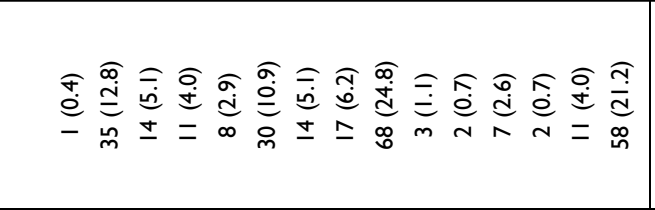 & 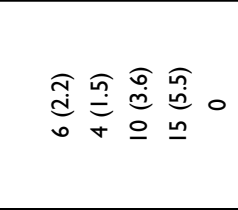 & 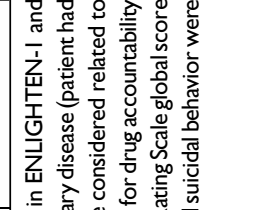 \\
\hline & 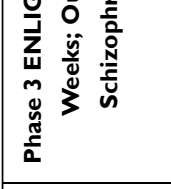 & 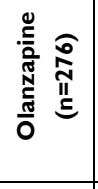 & 0 & $\stackrel{\substack{\mathfrak{d} \\
n}}{n}$ & $\begin{array}{l}\widehat{\widehat{\alpha}} \\
\stackrel{\sim}{\sim} \\
\stackrel{\sim}{\sim}\end{array}$ & 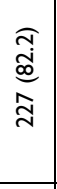 & 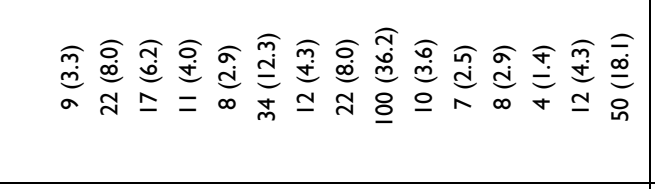 & 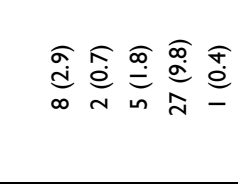 & 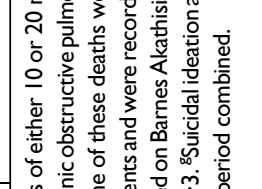 \\
\hline & 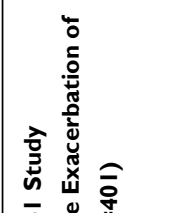 & 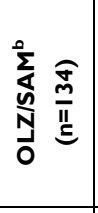 & $\circ$ & $\stackrel{\kappa}{e}$ & 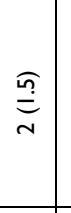 & 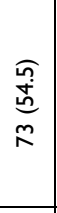 & 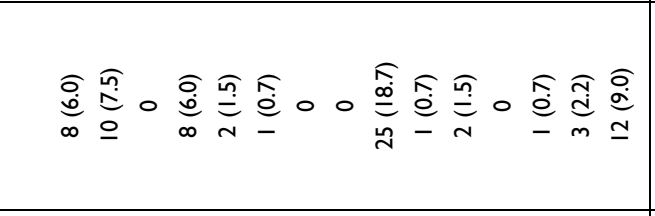 & 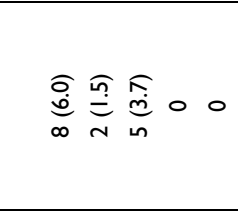 & 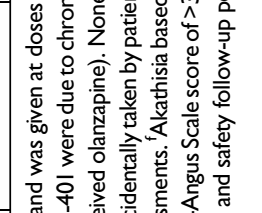 \\
\hline & 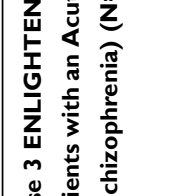 & 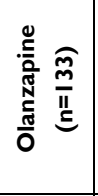 & $\stackrel{\widehat{\widehat{\infty}}}{\stackrel{0}{-}}$ & 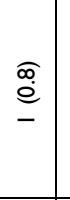 & 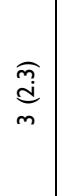 & 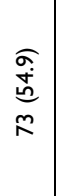 & 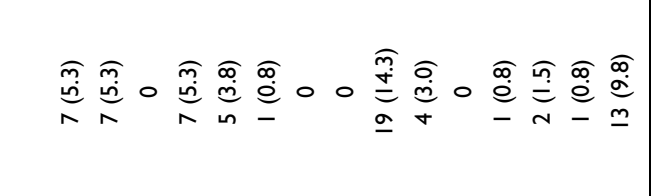 & 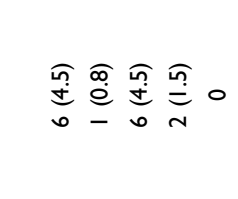 & 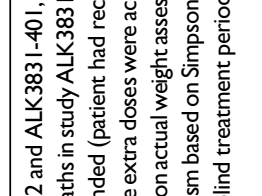 \\
\hline & 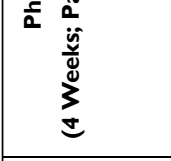 & 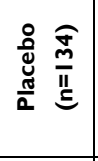 & $\circ$ & 0 & $\underset{\substack{\hat{n}\\
}}{n}$ & 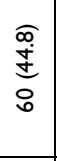 & 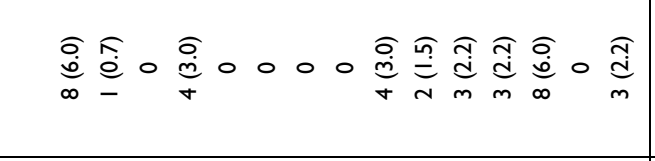 & 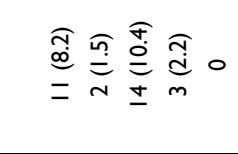 & 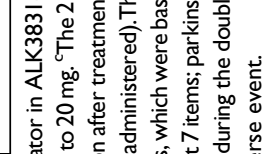 \\
\hline & 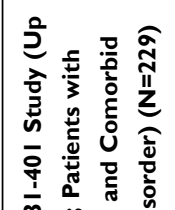 & 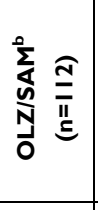 & 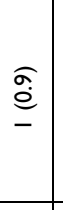 & $\begin{array}{l}\hat{N} \\
\stackrel{n}{n} \\
n\end{array}$ & $\begin{array}{l}\hat{\sigma} \\
\infty \\
\underline{\infty}\end{array}$ & 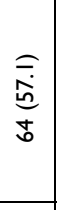 & 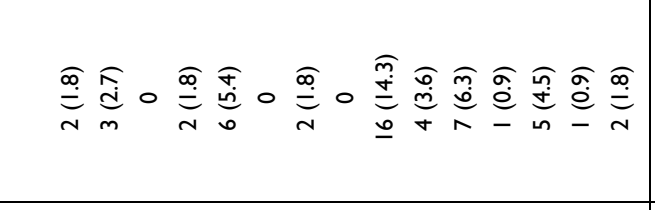 & 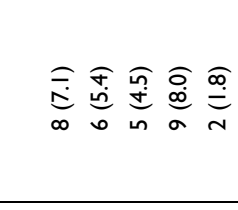 & 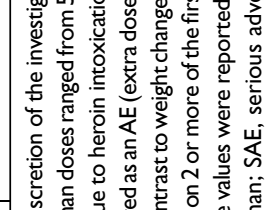 \\
\hline & 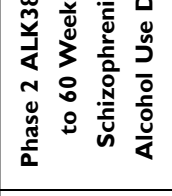 & 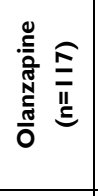 & 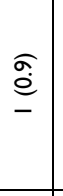 & 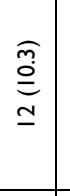 & 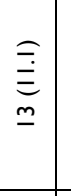 & 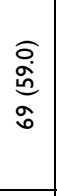 & 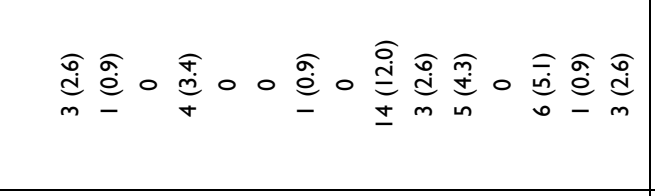 & 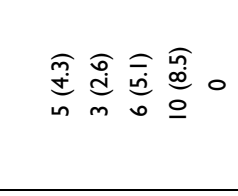 & 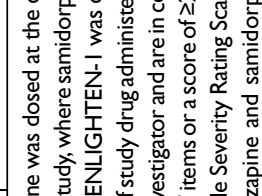 \\
\hline & 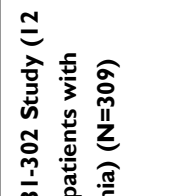 & 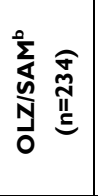 & $\circ$ & 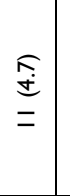 & $\frac{\widehat{a}}{\bar{a}}$ & 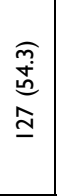 & 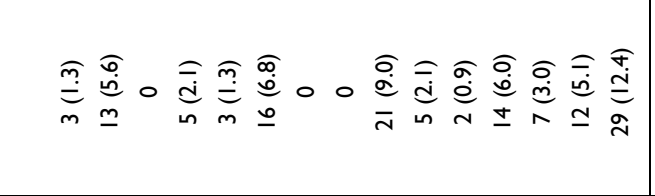 & 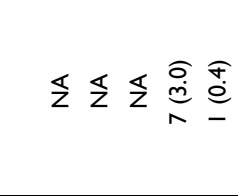 & 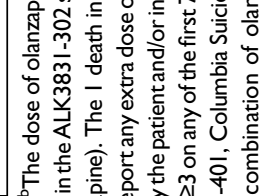 \\
\hline & 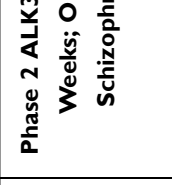 & 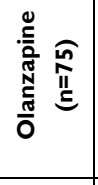 & 0 & $\underset{\substack{\text { d } \\
\text { N }}}{ }$ & $\underset{m}{\stackrel{\sigma}{\dot{+}}}$ & 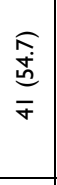 & 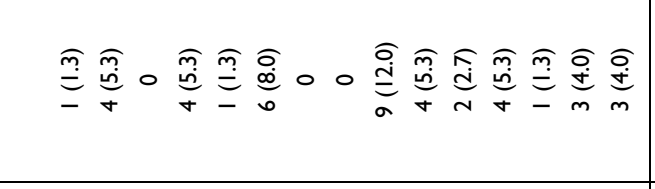 & $\mathbb{z} \mathbb{z} \underset{z}{\mathbb{E}} 0$ & 吾 \\
\hline & & & 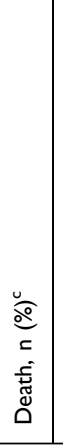 & 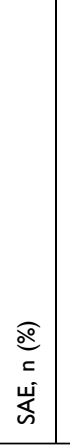 & 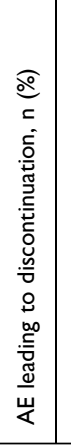 & 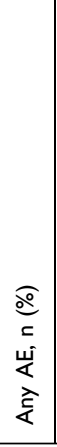 & 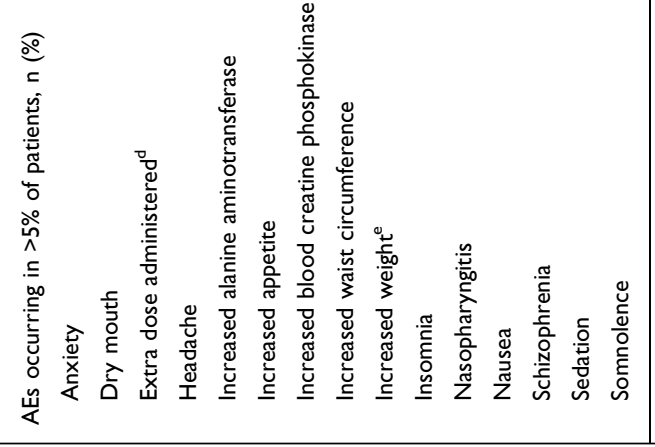 & 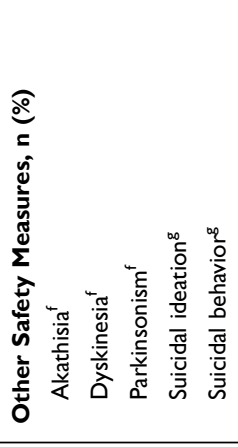 & 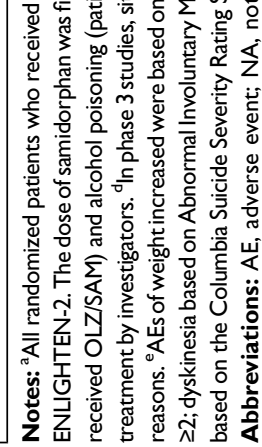 \\
\hline
\end{tabular}




\section{Adverse Events in Phase 3 Efficacy Trials}

The AE profile of OLZ/SAM was consistent with the known AE profile of olanzapine. In ENLIGHTEN 1, adverse events that occurred at least twice the rate of placebo with OLZ/SAM included increased weight, somnolence, dry mouth, and headache; these were similar in type and frequency to those reported in the olanzapine group (Table 3). ${ }^{61}$ In ENLIGHTEN-2, the most commonly reported AEs (in $\geq 10 \%$ of patients) associated with treatment were increased weight, somnolence, dry mouth, and increased appetite (Table 3). ${ }^{62}$ In both studies, rates of serious AEs and AEs leading to discontinuation were low and were similar between groups (Table 3).

\section{Long-Term Treatment Effects}

The long-term effects of OLZ/SAM on safety, tolerability, and symptoms of schizophrenia were investigated in two open-label, phase 3, 52-week extension studies, ENLIGHTEN-1-EXT and ENLIGHTEN-2-EXT ${ }^{74,75}$ that enrolled patients who completed the respective antecedent phase 3 studies. $^{61,62}$

Long-term tolerability was evidenced by low rates of AEs that led to treatment discontinuation: in both extension studies, the rate of discontinuation due to an $\mathrm{AE}$ was $\leq 6 \%{ }^{74,75}$ Additionally, neither extension study reported any clinically meaningful changes over time in hematology, biochemistry, vital signs, or electrocardiogram parameters. The incidence of extrapyramidal symptoms and

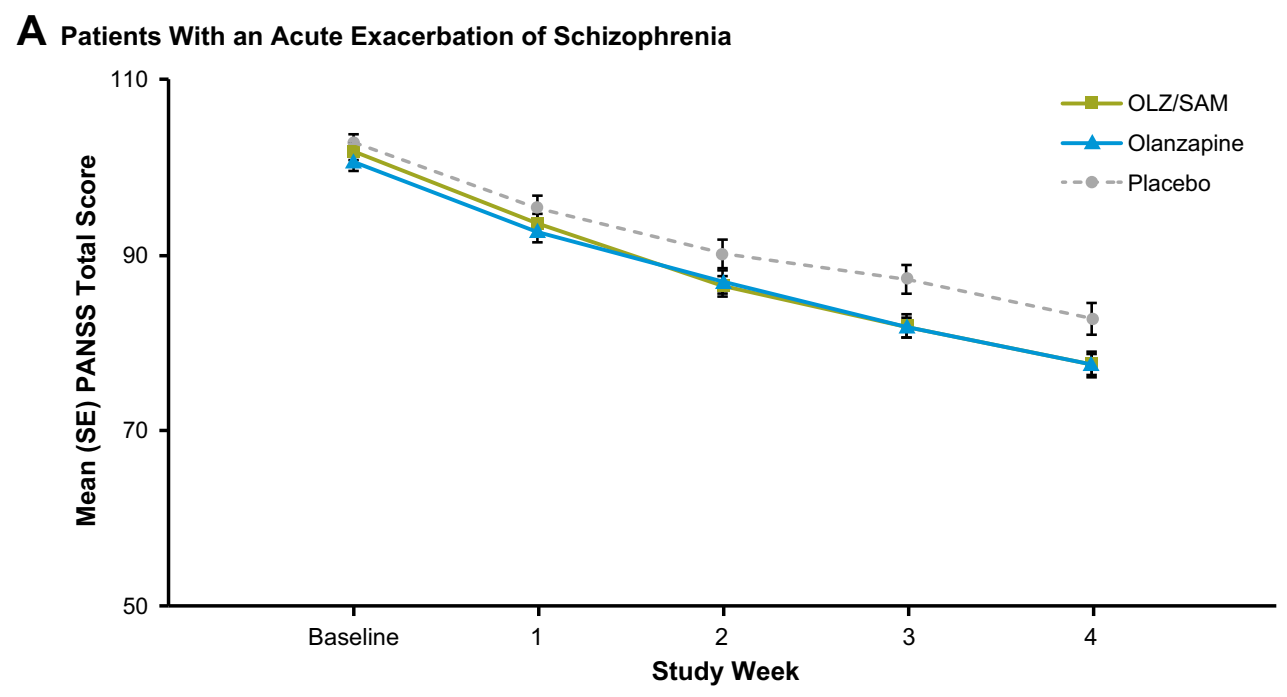

B Patients With Stable Schizophrenia

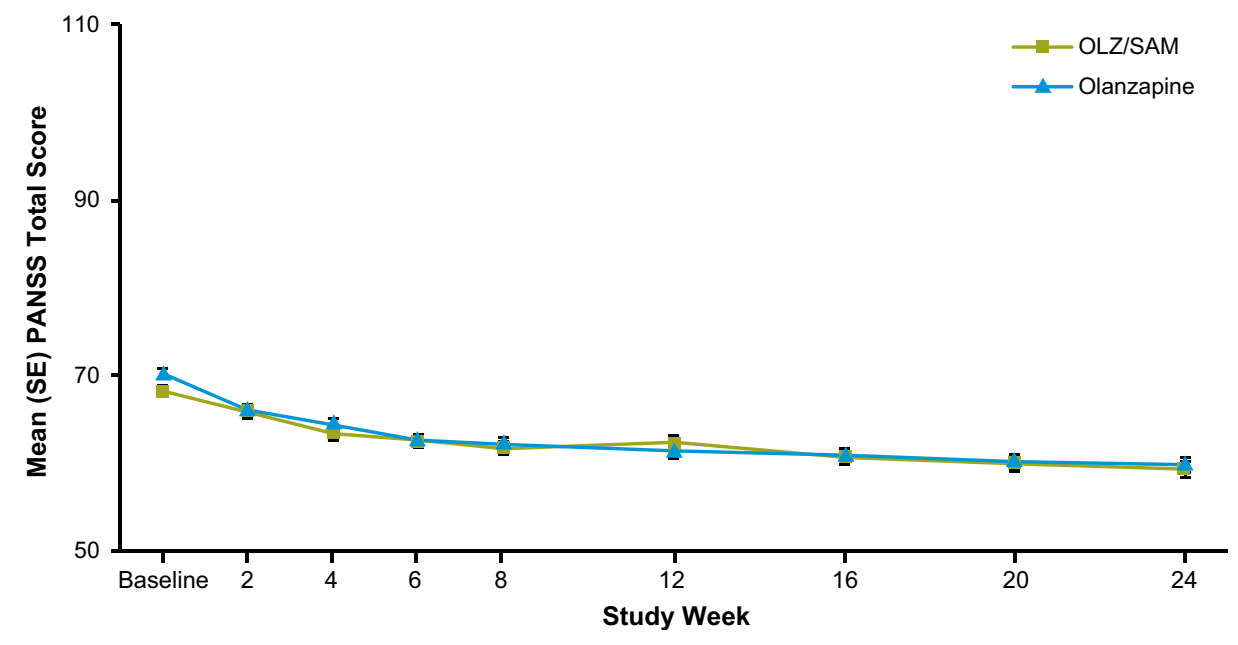

Figure I Continued. 


\section{Patients With Stable Schizophrenia (Phase 2)}

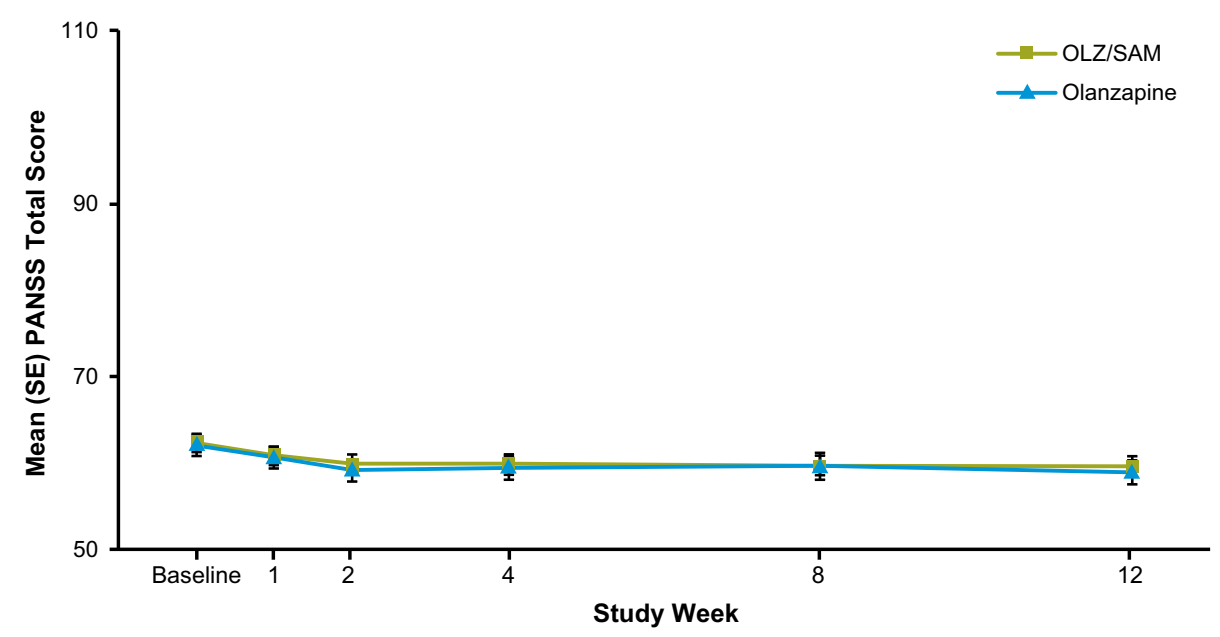

\section{Patients With Schizophrenia and Comorbid Alcohol Use Disorder (Phase 2)}

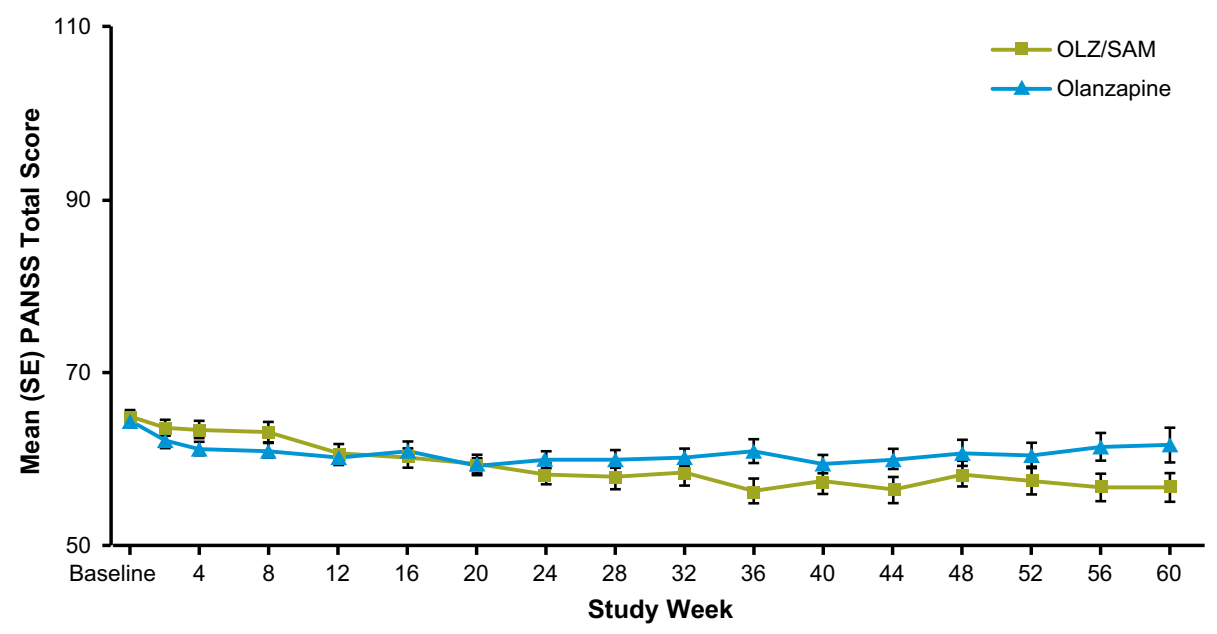

Figure I Antipsychotic effects of OLZ/SAM and olanzapine in key phase 2 and 3 studies. Graphs depict absolute changes in PANSS total scores over time by treatment group in the randomized, controlled (active or placebo), double-blind ENLIGHTEN-I (A), ENLIGHTEN-2 (B), ALK383I-302 (C), and ALK383 I-40I (D) studies. ${ }^{60-62,73}$ Panel (A) In the phase 3 ENLIGHTEN-I study, antipsychotic efficacy, as measured by the change from baseline in the PANSS total score at week 4, was the primary endpoint. The baseline characteristics of treatment groups in ENLIGHTEN-I were balanced. Panel (B) In the phase 2 ENLIGHTEN-2 study, antipsychotic efficacy, as measured by the change from baseline in the PANSS total score at week 24, was an "other" endpoint. The baseline characteristics of treatment groups in ENLIGHTEN-2 were balanced. Panel (C) In ALK383I-302, antipsychotic efficacy, as measured by the change from baseline in the PANSS total score at week 12 in the combined OLZ/SAM groups (OLZ/SAM 5/10 mg, I0/10 mg, and 20/10 mg) versus olanzapine was the primary endpoint; only the olanzapine + placebo and olanzapine + samidorphan 10-mg groups are presented here to allow cross-study comparisons. Panel (D) In ALK383I-40I, antipsychotic efficacy, as measured by the change from baseline in the PANSS total score, was an "other" efficacy endpoint. Graph depicts observed changes with an MMRM approach. Abbreviations: OLZ/SAM, combination of olanzapine and samidorphan; MMRM, mixed-model repeated measures; PANSS, Positive and Negative Syndrome Scale; SE, standard error.

suicidality was low in both long-term extension studies (Table 3).

Importantly, OLZ/SAM was effective in controlling symptoms of schizophrenia over 52 weeks of treatment (Table 2; Figure 5A and B), as evidenced by sustained improvements in PANSS and CGI-S scores over time. However, in contrast to what has been described with long-term olanzapine treatment, weight remained stable during open-label OLZ/SAM treatment in both long- term extension studies (Figure $5 \mathrm{C}$ and D). ${ }^{74,75}$ The observed long-term changes in weight were consistent with weight changes observed with other second-generation antipsychotics, although comparisons to other antipsychotics must be interpreted cautiously owing to different study objectives, designs, and analyses, and to the lack of comparators in these studies. ${ }^{96-99}$ Waist circumference also remained stable during long-term OLZ/SAM treatment. ${ }^{75}$ 
A

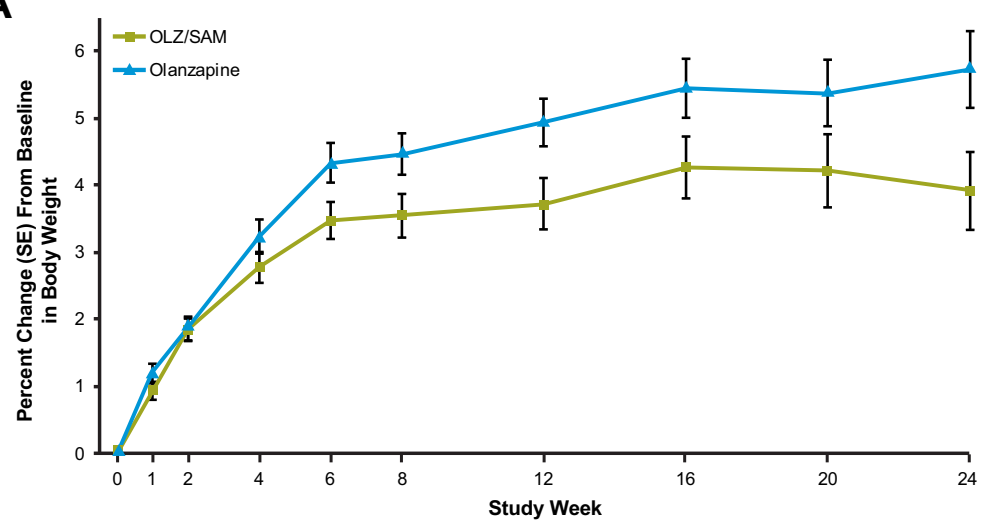

B

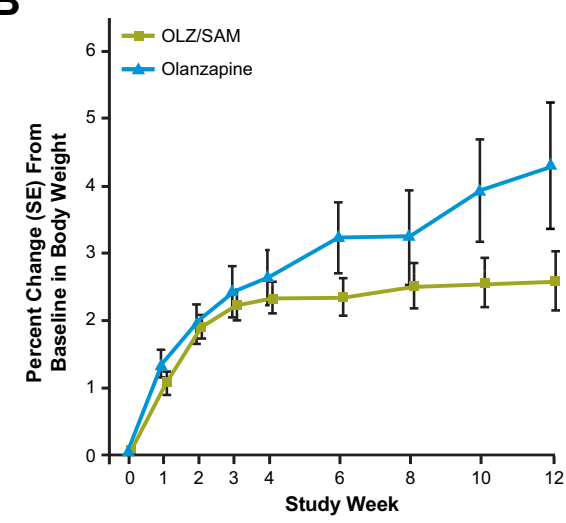

C

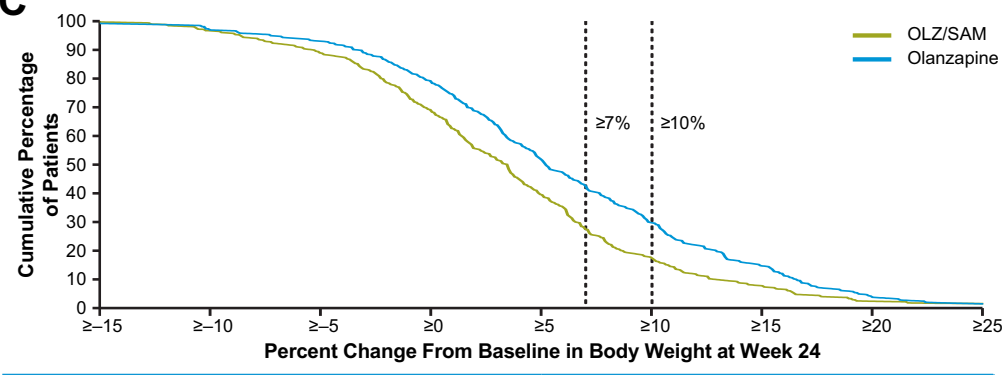

\begin{tabular}{|l|c|c|c|}
\hline Parameter & $\begin{array}{c}\text { OLZ/SAM } \\
(\mathrm{n}=266)\end{array}$ & $\begin{array}{c}\text { Olanzapine } \\
(\mathrm{n}=262)\end{array}$ & $\begin{array}{c}\text { OLZ/SAM vs Olanzapine } \\
\text { Odds Ratio }\end{array}$ \\
\hline Proportion of patients with weight gain $\geq 10 \%$ from baseline at week 24 & $17.8 \%$ & $29.8 \%$ & 0.50 \\
\hline Proportion of patients with weight gain $\geq 7 \%$ from baseline at week 24 & $27.5 \%$ & $42.7 \%$ & 0.50 \\
\hline
\end{tabular}

Figure 2 Weight effects of patients treated with OLZ/SAM and olanzapine: the mean (SE) percent change in weight from baseline for ENLIGHTEN-2 (A) and for ALK383 I302 (B), and the cumulative frequency distribution of percent change from baseline in body weight at week 24 (C). In ENLIGHTEN-2, the baseline characteristics of treatment groups in ENLIGHTEN-2 were balanced. Panel (C) depicts how OLZ/SAM reduced the risk of weight gain relative to olanzapine across a wide range of cutoffs; this plot presents the range of weight changes at week 24 on the $x$ axis (ranging from a weight loss of $15 \%$ weight loss [-15\%] to a weight gain of $25 \%$ ) versus the proportion of patients gaining this amount of weight or more on the $y$ axis. The curve for OLZ/SAM generally falls below the curve for olanzapine, indicating that a smaller proportion of patients treated with OLZ/SAM experienced weight gain across the majority of cutoffs, including gaining any weight ( $\geq 0 \%$ ) or at more substantial levels of weight gain (eg, $\geq 7$ and $10 \%$ cutoffs [marked in the figure by vertical dotted lines]). Observed data are depicted in panels (A (MMRM approach) and B). Panel (C) reprinted with permission from the American Journal of Psychiatry (Copyright (2020). American Psychiatric Association. All Rights Reserved. ${ }^{62}$

Abbreviations: MMRM, mixed-model repeated measures; OLZ/SAM, combination of olanzapine and samidorphan; SE, standard error.

In general, long-term changes in metabolic laboratory parameter values were small and remained stable (Supplemental Table 3) ${ }^{74,75}$ In addition, there was little change in glycosylated hemoglobin (hemoglobin A1c) values, suggesting that glycemic control was maintained with long-term OLZ/SAM treatment. ${ }^{74,75}$

Results from numerous long-term treatment studies have indicated that patients discontinue olanzapine less frequently, or take longer to do so, compared with most other antipsychotics, and this is attributed to its efficacy in treating and controlling symptoms. ${ }^{18-20}$ In the OLZ/SAM extension studies, the effectiveness of OLZ/SAM in controlling symptoms of schizophrenia was supported by the low rates of all-cause discontinuation, with nearly two thirds of patients $(66.1 \%$ in ENLIGHTEN-1-EXT; $63.0 \%$ in ENLIGHTEN-2-EXT) completing the respective treatment periods. ${ }^{74,75}$ This completion rate is higher than what is typically observed in similar 1-year extension studies with other antipsychotics (ie, brexpiprazole, cariprazine, and lurasidone), which average less than a $50 \%$ completion rate. ${ }^{96-100}$ Time to all-cause discontinuation is presented graphically for each extension study in Figure 5E and F.

Results from the long-term extension studies should be considered in light of some limitations: (1) these were singlearm, open-label studies (ie, randomization was lost at study entry) without comparators, (2) the interpretation of longterm data may be impacted by missing data due to patient discontinuations over the long study duration, and (3) the studies may have selected for patients who responded favorably to OLZ/SAM treatment in the preceding studies.

\section{Other Populations}

The efficacy, safety, and tolerability of OLZ/SAM compared with olanzapine have also been examined in patients with 


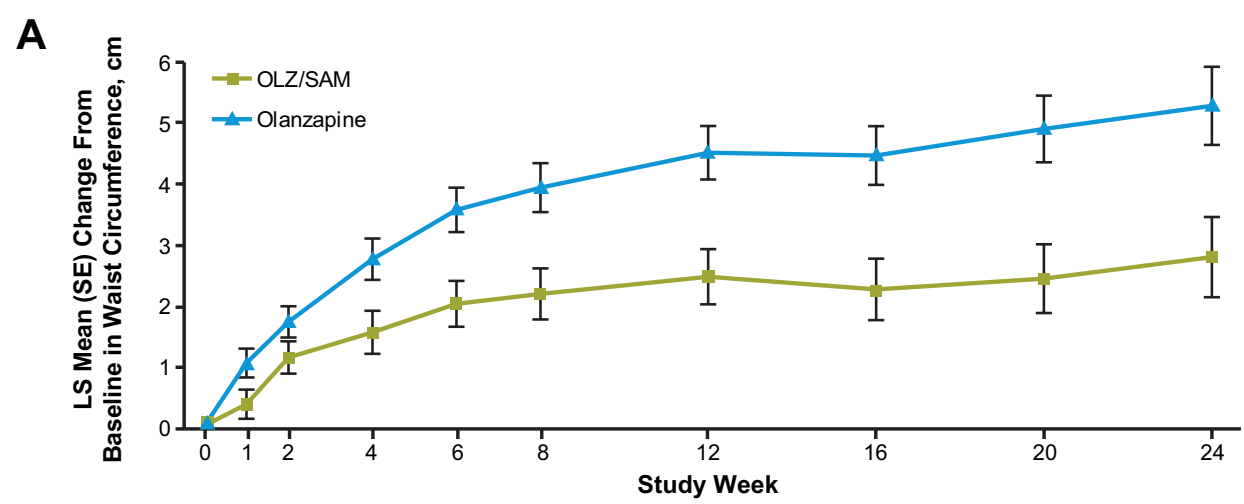

B

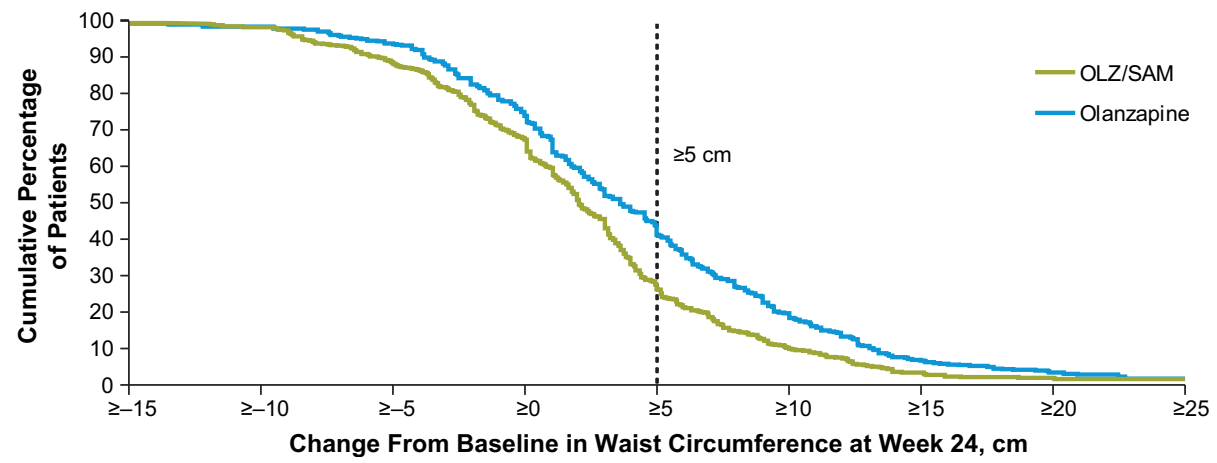

Figure 3 Effects on waist circumference profiles in patients treated with OLZ/SAM and olanzapine in ENLIGHTEN-2. (A) LS mean change from baseline in waist circumference and (B) cumulative frequency distribution of percent change from baseline in waist circumference at week 24 . The waist circumference analysis presented in Panel $(\mathbf{A})$ is based on an ANCOVA model with a multiple imputation approach for missing postbaseline assessments. ${ }^{62}$ Panel (A) reprinted with permission from the American Journal of Psychiatry (Copyright @2020). American Psychiatric Association. All Rights Reserved. ${ }^{62}$

Abbreviations: ANCOVA, analysis of covariance; LS, least squares; OLZ/SAM, combination of olanzapine and samidorphan; SE, standard error.

schizophrenia and comorbid alcohol use disorder. ${ }^{73,101}$ In this study, while treatment with OLZ/SAM or olanzapine resulted in similar times to a composite endpoint of worsening illness and there was no added benefit of OLZ/SAM compared with olanzapine with regard to drinking behaviors, patients in both treatment groups had reduced alcohol use and improved psychiatric symptoms. Overall, OLZ/SAM treatment for up to 9 months was generally well tolerated in this patient population (safety data are summarized in Table 3). In addition, treatment with OLZ/SAM resulted in similar effectiveness to olanzapine in controlling symptoms of schizophrenia, based on changes in PANSS total scores over 60 weeks (Figure 1D). ${ }^{73}$

\section{Evidence for the Use of OLZ/SAM in Bipolar I Disorder}

OLZ/SAM is approved in the United States for treatment of manic or mixed episodes in BD-I, as monotherapy or as an adjunct to lithium or valproate, as well as for maintenance monotherapy in BD-I. The efficacy of OLZ/SAM in the treatment of adult patients with BD-I has been established based on adequate and well-controlled studies of orally administered olanzapine. ${ }^{40}$ Additionally, the olanzapine component of OLZ/SAM was shown to be bioequivalent to olanzapine in the branded product, Zyprexa. $^{64}$ Furthermore, treatment with OLZ/SAM had no clinically significant effect on lithium or valproate pharmacokinetics. ${ }^{68}$ In schizophrenia patients, samidorphan did not negatively affect the efficacy of olanzapine when administered as OLZ/SAM ${ }^{59}$ Finally, OLZ/SAM consistently mitigated olanzapine-associated weight gain across a range of species/populations (eg, rodents, nonhuman primates, healthy individuals, and patients with schizophrenia), ${ }^{60,62,71}$ and antipsychotic-associated weight gain and metabolic dysregulation occur independently of disease. $^{102-104}$

\section{Clinical Perspectives}

Most second-generation antipsychotics used in the context of serious mental illness are associated with weight gain, ${ }^{14}$ which may lead to detrimental effects in patients, including lower self-esteem and the potential for negative 
A

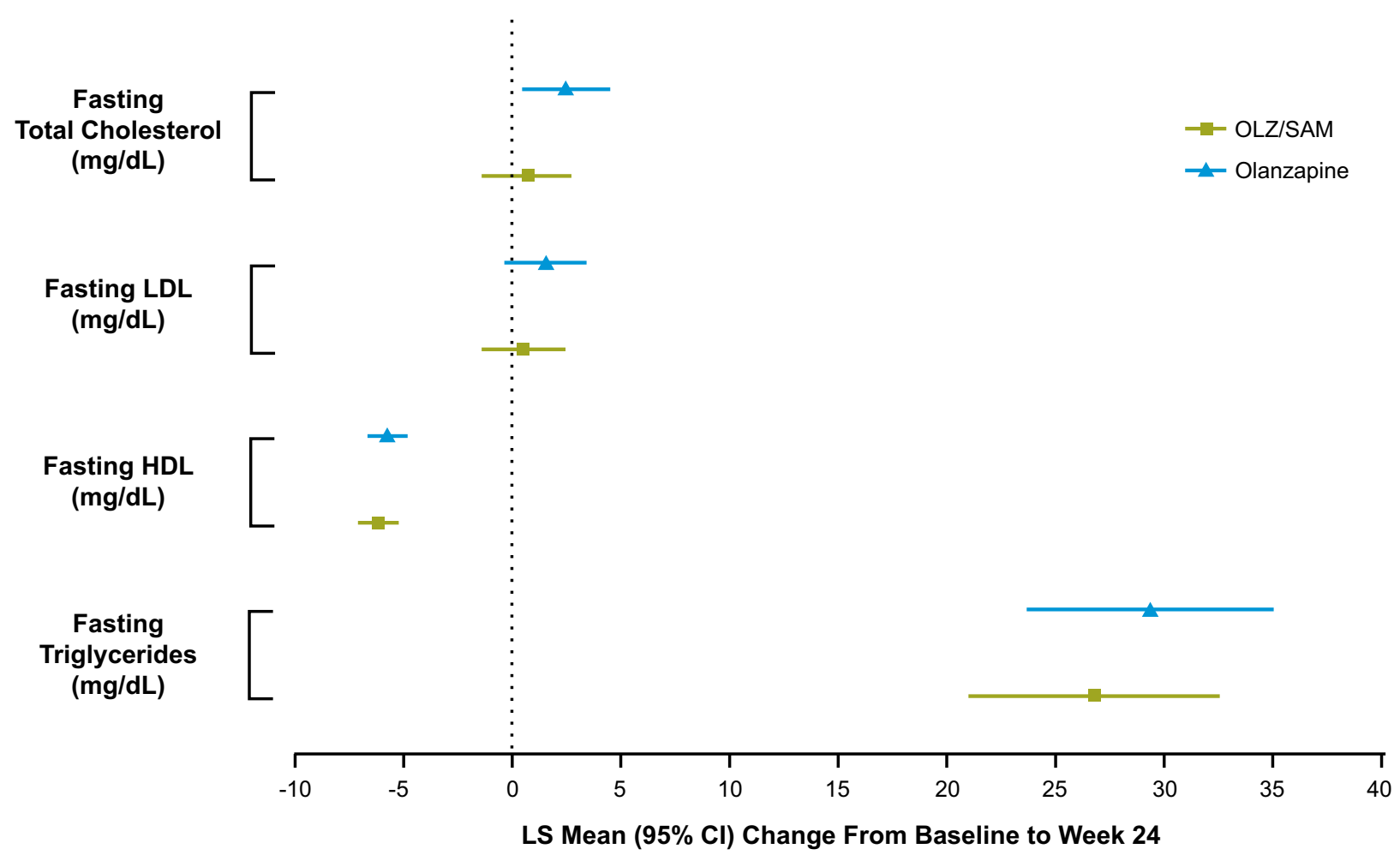

$\mathbf{B}$

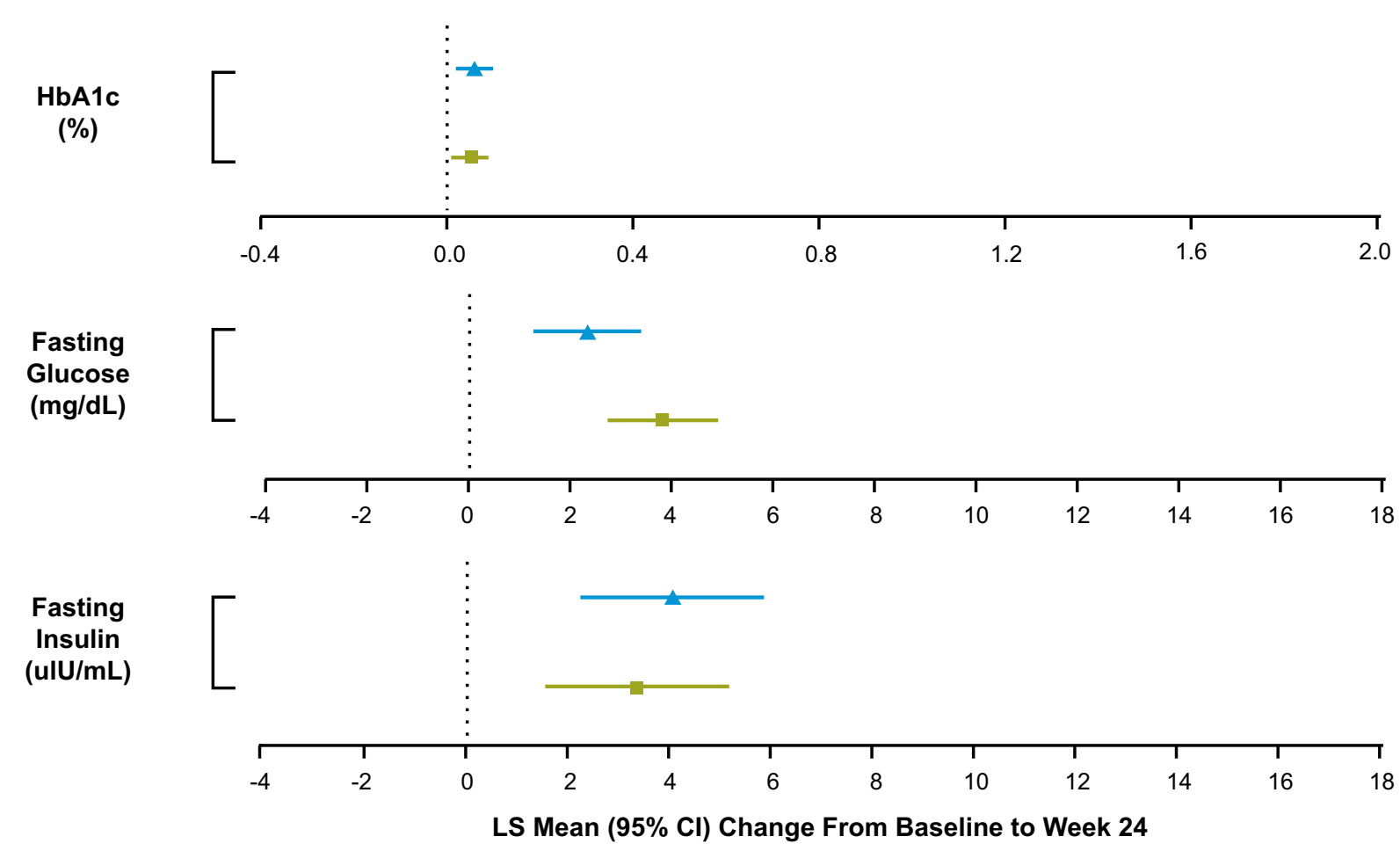

Figure 4 ENLIGHTEN-2 metabolic laboratory parameters: LS mean $(95 \% \mathrm{Cl})$ changes from baseline to week 24 for $(\mathbf{A})$ fasting lipids and (B) HbAlc, fasting glucose, and fasting insulin. Values are based on a mixed model with repeated measures using observed data.

Abbreviations: $\mathrm{Cl}$, confidence interval; HbAlc, hemoglobin AIc; HDL, high-density lipoprotein; LDL, low-density lipoprotein; LS, least squares; OLZ/SAM, combination of olanzapine and samidorphan. 

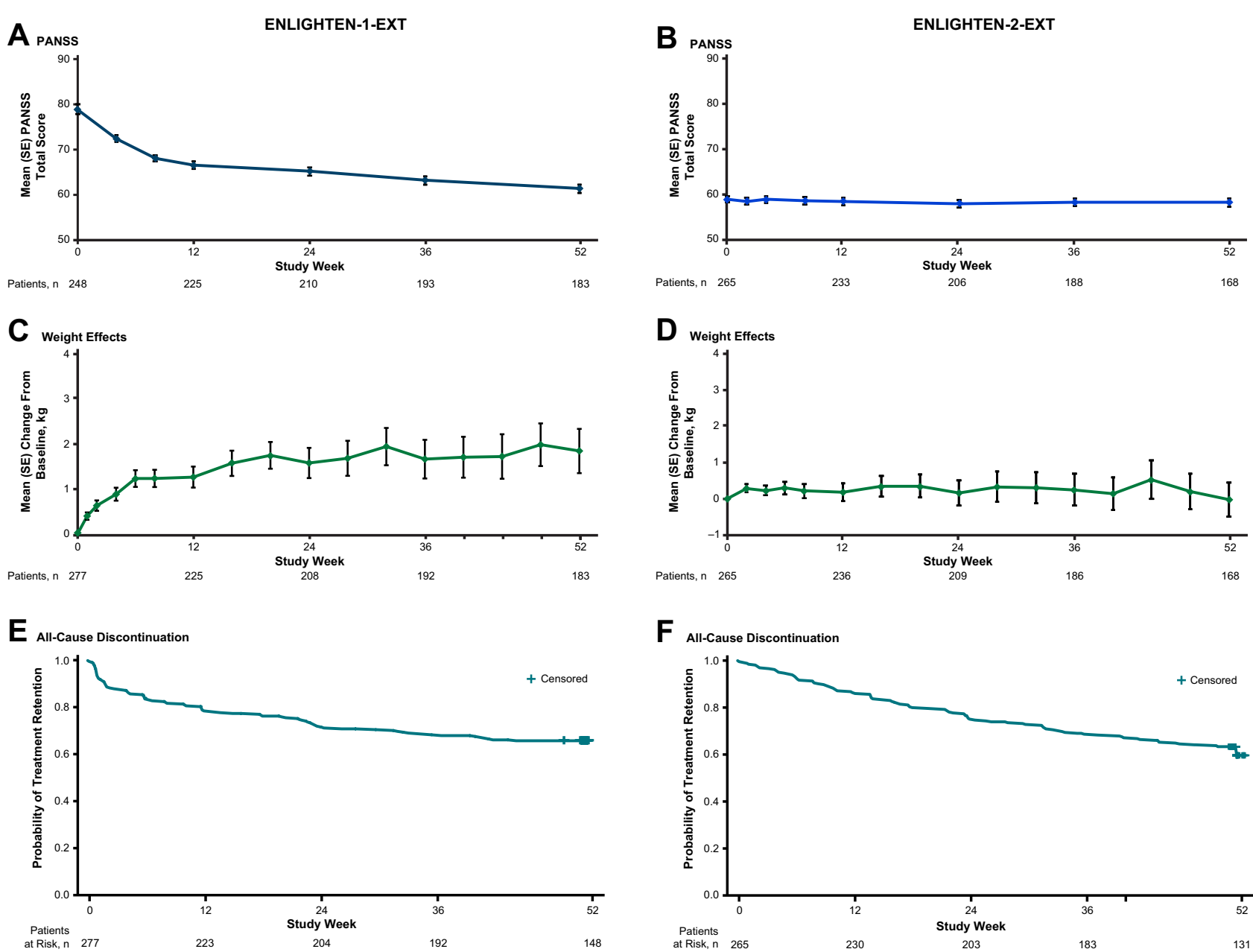

$\mathbf{F}$

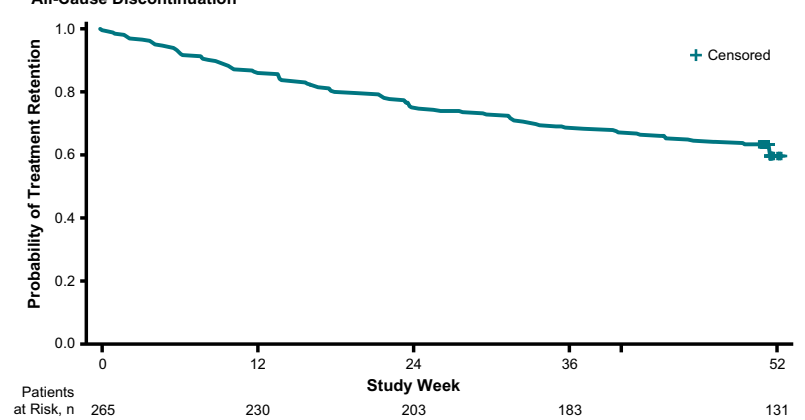

Figure 5 Antipsychotic effects, weight effects, and time to all-cause discontinuation in ENLIGHTEN-I-EXT ${ }^{74}$ (A, C, E) and ENLIGHTEN-2-EXT ${ }^{75}$ (B, D, F), respectively. Data presented above are in all patients; in both studies, all patients received OLZ/SAM treatment. Prior to entering ENLIGHTEN-I-EXT, patients participated in the 4-week ENLIGHTEN-I study, where entry criteria specified that patients had to be experiencing an acute exacerbation of schizophrenia. Prior to entering ENLIGHTEN-2-EXT, patients participated in the 24-week ENLIGHTEN-2 study, where entry criteria specified that patients with schizophrenia be stable outpatients. In all panels, baseline/week 0 refers to extension study start. Panels (B, D, and F) are reprinted with permission from Schizophrenia Research (Copyright @2021). ${ }^{75}$

Abbreviations: EXT, extension; OLZ/SAM, combination of olanzapine and samidorphan; PANSS, Positive and Negative Syndrome Scale; SE, standard error.

outcomes when patients do not fill prescriptions or take their medication. ${ }^{105-108}$ Additionally, excess weight gain may exacerbate cardiometabolic risk factors, ${ }^{45,109}$ especially in people with serious mental illness, including those with schizophrenia or BD-I. ${ }^{110,111}$ This is partially attributable to the rising prevalence of obesity in the general population, and in patients with schizophrenia and BD-I in particular. ${ }^{112-114}$ Additionally, patients with serious mental illness have an increased prevalence of risk factors for cardiovascular disease relative to the general population, which contributes to excess early mortality in these patients. ${ }^{115-117}$

Up until now, there have not been any FDA-approved agents that address the specific issue of antipsychoticinduced weight gain. Several potential strategies have been investigated to reduce or mitigate antipsychotic-associated weight gain, including both nonpharmacologic and pharmacologic interventions. With some exceptions, studies of pharmacologic options have mostly assessed weight reduction in patients who have already experienced weight gain, rather than investigating the prevention of antipsychotic-associated weight gain from the outset. ${ }^{118}$

An example of an "off-label" pharmacologic intervention that has been extensively studied is adjunctive metformin. In a meta-analysis of 32 randomized studies evaluating 15 pharmacologic agents for minimizing or attenuating antipsychoticassociated weight gain, metformin outperformed other agents versus placebo. ${ }^{119}$ In the 7 trials (lasting 6 to 16 weeks) informing that analysis, metformin treatment was associated with a weight loss of $-2.94 \mathrm{~kg}$ versus placebo in patients who 
had already experienced antipsychotic-associated weight gain. ${ }^{119}$ However, this meta-analysis did not detect a weight change difference versus placebo when metformin was initiated concomitantly with antipsychotics. ${ }^{119}$ In an updated systematic review and meta-analysis on this topic that included 10 metformin studies, ${ }^{118}$ a mean $3.17-\mathrm{kg}$ reduction in weight versus placebo was observed across studies. However, 3 of the 4 studies that investigated the prevention of antipsychoticassociated weight gain with metformin were negative, ${ }^{120-122}$ while one was positive in patients who completed the study. ${ }^{123}$

For other pharmacologic interventions that have been assessed for minimizing antipsychotic-associated weight, there is inadequate evidence of effect, no clinical benefit, or an AE profile that offsets any potential benefits for reducing existing antipsychotic-associated weight gain. ${ }^{124}$ Current guidelines suggest that the use of such agents should be considered in the context of limited long-term data and the potential for AEs. ${ }^{11}$ Because OLZ/SAM is a single tablet, concerns regarding adding medications onto an existing regimen to reduce weight (eg, AEs, drug-drug interaction effects, and pill burden) may be avoided.

Appropriate antipsychotic selection for an individual patient requires that clinicians consider the benefits and risks of the treatment, as well as bearing in mind an individual patient's characteristics and treatment goals. For patients who may benefit from the established efficacy of olanzapine, clinicians have to balance choosing this highly effective therapy for their patient while risking other safety concerns, including the risk of significant weight gain and its associated long-term health consequences. $^{32,33}$ OLZ/SAM may be an option in this regard, as it provides similar efficacy compared with olanzapine but with significantly less weight gain. The weightmitigating effects of OLZ/SAM relative to olanzapine have been replicated in at least 2 studies and is supported by long-term data extending over 1 year. $^{41,125,126}$ For certain patients who are at greater risk of antipsychoticassociated weight gain, including those with a lower body mass index ${ }^{41,125,126}$ and those with less prior exposure to antipsychotics (eg, patients early in illness), OLZ/SAM may also be useful. ${ }^{127,128}$ However, it should be noted that, because OLZ/SAM contains the opioid antagonist samidorphan, it should not be used in patients using opioids or in those undergoing acute opioid withdrawal. ${ }^{59}$

One ongoing OLZ/SAM study will provide additional long-term safety and tolerability data (NCT03201757). Another ongoing study (NCT03187769; ENLIGHTEN-
Early) is assessing treatment effects of OLZ/SAM in patients early in their disease course with schizophrenia, schizophreniform disorder, or BD-I.

\section{Conclusions}

OLZ/SAM provides the established efficacy of olanzapine while mitigating olanzapine-associated weight gain through opioid receptor blockade. Studies to date have characterized the pharmacokinetics, safety, and efficacy (both antipsychotic and weight efficacy) of OLZ/SAM. Clinical pharmacokinetic data indicate the feasibility of once-daily dosing with OLZ/SAM and provide support for the use of OLZ/SAM in BD-I based on bioequivalence of OLZ/SAM to olanzapine and the lack of clinically significant effects of adjunctive OLZ/SAM on lithium or valproate pharmacokinetics. The antipsychotic and weight gain mitigation efficacy of OLZ/SAM was observed in multiple studies; these effects were durable and were maintained during open-label treatment. Overall, data from more than 1600 patients in studies of differing designs, durations, and treatment populations indicate an AE profile for OLZ/SAM that is similar to that of olanzapine, with the exception of less weight gain. Taken together, these data support the recent approval of OLZ/SAM as a clinically useful option for patients with schizophrenia or BD-I and its suitability for long-term treatment.

\section{Abbreviations}

$1^{\circ} \mathrm{EP}$, prespecified primary endpoint; $2^{\circ} \mathrm{EP}$, prespecified secondary endpoint; AE, adverse event; ANCOVA, analysis of covariance; $\mathrm{AUC}_{\infty}$, area under the plasma concentrationtime curve from time 0 to infinity; BD-I, bipolar I disorder; CGI-S, Clinical Global Impression-Severity; $\mathrm{C}_{\max }$, maximum plasma concentration; CYP, cytochrome P450 enzyme; ENLIGHTEN-1-EXT, 52-week extension study of ENLIGHTEN-1; ENLIGHTEN-2-EXT, 52-week extension study of ENLIGHTEN-2; HbA1c, hemoglobin A1c; HDL, high-density lipoprotein; LDL, low-density lipoprotein; LS, least squares; MMRM, mixed-model repeated measures; NA, not assessed; NNT, number needed to treat; OL, open-label; OLZ/SAM, a combination of olanzapine and samidorphan; PANSS, Positive and Negative Syndrome Scale; PK, pharmacokinetics; QT(c), (corrected) QT interval; $\mathrm{R}, \mathrm{DB}, \mathrm{C}$, randomized, double-blind, controlled (placebo and/or active comparator) trial; SAE, serious adverse event; UGT, uridine 5'-diphospho-glucuronosyltransferase; WHO, World Health Organization. 


\section{Acknowledgments}

Medical writing and editorial support were provided by Gina Daniel, PhD, and John H. Simmons, MD, of Peloton Advantage, LLC, an OPEN Health company, and funded by Alkermes, Inc.

\section{Author Contributions}

All authors made a significant contribution to the work reported, whether that is in the conception, study design, execution, acquisition of data, analysis and interpretation, or in all these areas; took part in drafting, revising or critically reviewing the article; gave final approval of the version to be published; have agreed on the journal to which the article has been submitted; and agree to be accountable for all aspects of the work.

\section{Disclosure}

These studies were sponsored by Alkermes, Inc. L. Citrome reports being a Consultant for AbbVie/Allergan, Acadia, Adamas, Alkermes, Angelini, Astellas, Avanir, Axsome, BioXcel, Boehringer Ingelheim, Cadent Therapeutics, Eisai, Impel, Intra-Cellular Therapies, Janssen, Karuna, Lundbeck, Lyndra, Medavante-ProPhase, Merck, Neurocrine, Novartis, Noven, Otsuka, Ovid, Relmada, Reviva, Sage, Sunovion, Teva, and University of Arizona and providing one-off ad hoc consulting for individuals/ entities conducting marketing, commercial, or scientific scoping research; being a Speaker for AbbVie/Allergan, Acadia, Alkermes, Angelini, Eisai, Intra-Cellular Therapies, Janssen, Lundbeck, Neurocrine, Noven, Otsuka, Sage, Sunovion, Takeda, Teva, and CME activities organized by medical education companies such as Medscape, NACCME, NEI, Vindico, and Universities and Professional Organizations/Societies; owning stock (small number of shares of common stock) at Bristol-Myers Squibb, Eli Lilly, J \& J, Merck, and Pfizer purchased $>10$ years ago; and receiving royalties from Wiley (Editor-inChief, International Journal of Clinical Practice, through end of 2019), UpToDate (reviewer), Springer Healthcare (book), and Elsevier (Topic Editor, Psychiatry, Clinical Therapeutics).

C. Graham, A. Simmons, M.S. Todtenkopf, H. Cummings, and L. Sun are employees of Alkermes, Inc. Y. Jiang, B. Silverman, and L. DiPetrillo were employees of Alkermes, Inc., at the time of these studies. D. McDonnell is an employee of Alkermes Pharma Ireland Ltd. Dr Mark S. Todtenkopf has patents 8778960 (Methods for treating antipsychotic-induced weight gain; the other patents are for the same indication and are a part of a subset/family), 16/ 899708 (pending), 17/071166, and 17/071236. The authors report no other conflicts of interest in this work.

\section{References}

1. Owen MJ, Sawa A, Mortensen PB. Schizophrenia. Lancet. 2016;388(10039):86-97.

2. GBD. 2016 Disease and Injury Incidence and Prevalence Collaborators. Global, regional, and national incidence, prevalence, and years lived with disability for 328 diseases and injuries for 195 countries, 1990-2016: a systematic analysis for the Global Burden of Disease Study 2016. Lancet. 2017;390(10100):12111259.

3. Sanchez-Moreno J, Martinez-Aran A, Tabares-Seisdedos R, Torrent C, Vieta E, Ayuso-Mateos JL. Functioning and disability in bipolar disorder: an extensive review. Psychother Psychosom. 2009;78(5):285-297.

4. Laursen TM, Munk-Olsen T, Gasse C. Chronic somatic comorbidity and excess mortality due to natural causes in persons with schizophrenia or bipolar affective disorder. PLoS One. 2011;6(9): e24597.

5. De Hert M, Correll CU, Bobes J, et al. Physical illness in patients with severe mental disorders. I. Prevalence, impact of medications and disparities in health care. World Psychiatry. 2011;10 (1):52-77.

6. Olfson M, Gerhard T, Huang C, Crystal S, Stroup TS. Premature mortality among adults with schizophrenia in the United States. JAMA Psychiatry. 2015;72(12):1172-1181.

7. Schaffer A, Isometsa ET, Tondo L, et al. Epidemiology, neurobiology and pharmacological interventions related to suicide deaths and suicide attempts in bipolar disorder: part I of a report of the International Society for Bipolar Disorders Task Force on Suicide in Bipolar Disorder. Aust N Z J Psychiatry. 2015;49 (9):785-802.

8. Laursen TM, Nordentoft M, Mortensen PB. Excess early mortality in schizophrenia. Annu Rev Clin Psychol. 2014;10:425448.

9. Hayes JF, Miles J, Walters K, King M, Osborn DP. A systematic review and meta-analysis of premature mortality in bipolar affective disorder. Acta Psychiatr Scand. 2015;131(6):417-425.

10. Yatham LN, Kennedy SH, Parikh SV, et al. Canadian Network for Mood and Anxiety Treatments (CANMAT) and International Society for Bipolar Disorders (ISBD) 2018 guidelines for the management of patients with bipolar disorder. Bipolar Disord. 2018;20(2):97-170.

11. American Psychiatric Association. The American Psychiatric Association Practice Guideline for the Treatment of Patients with Schizophrenia. Washington, DC: American Psychiatric Association; 2019.

12. Stroup TS, Gray N. Management of common adverse effects of antipsychotic medications. World Psychiatry. 2018;17(3):341356.

13. Haddad PM, Brain C, Scott J. Nonadherence with antipsychotic medication in schizophrenia: challenges and management strategies. Patient Relat Outcome Meas. 2014;5:43-62.

14. De Hert M, Detraux J, van Winkel R, Yu W, Correll CU. Metabolic and cardiovascular adverse effects associated with antipsychotic drugs. Nat Rev Endocrinol. 2012;8(2):114-126.

15. Kahn RS, Sommer IE, Murray RM, et al. Schizophrenia. Nat Rev Dis Primers. 2015;1:15067. 
16. Bauer M, Andreassen OA, Geddes JR, et al. Areas of uncertainties and unmet needs in bipolar disorders: clinical and research perspectives. Lancet Psychiatry. 2018;5(11):930-939.

17. Citrome L, Eramo A, Francois C, et al. Lack of tolerable treatment options for patients with schizophrenia. Neuropsychiatr Dis Treat. 2015;11:3095-3104.

18. Lieberman JA, Stroup TS, McEvoy JP, et al. Effectiveness of antipsychotic drugs in patients with chronic schizophrenia. $N$ Engl J Med. 2005;353(12):1209-1223.

19. Kahn RS, Fleischhacker WW, Boter H, et al. Effectiveness of antipsychotic drugs in first-episode schizophrenia and schizophreniform disorder: an open randomised clinical trial. Lancet. 2008;371(9618):1085-1097.

20. Haro JM, Suarez D, Novick D, Brown J, Usall J, Naber D. Threeyear antipsychotic effectiveness in the outpatient care of schizophrenia: observational versus randomized studies results. Eur Neuropsychopharmacol. 2007;17(4):235-244.

21. Takahashi M, Nakahara N, Fujikoshi S, Iyo M. Remission, response, and relapse rates in patients with acute schizophrenia treated with olanzapine monotherapy or other atypical antipsychotic monotherapy: 12-month prospective observational study. Pragmat Obs Res. 2015;6:39-46.

22. Novick D, Haro JM, Suarez D, Vieta E, Naber D. Recovery in the outpatient setting: 36-month results from the Schizophrenia Outpatients Health Outcomes (SOHO) study. Schizophr Res. 20 09;108(1-3):223-230.

23. Leucht S, Cipriani A, Spineli L, et al. Comparative efficacy and tolerability of 15 antipsychotic drugs in schizophrenia: a multiple-treatments meta-analysis. Lancet. 2013;382(9896): 951-962.

24. Kishimoto T, Hagi K, Nitta M, Kane JM, Correll CU. Long-term effectiveness of oral second-generation antipsychotics in patients with schizophrenia and related disorders: a systematic review and meta-analysis of direct head-to-head comparisons. World Psychiatry. 2019;18(2):208-224.

25. Kinon BJ, Liu-Seifert H, Adams DH, Citrome L. Differential rates of treatment discontinuation in clinical trials as a measure of treatment effectiveness for olanzapine and comparator atypical antipsychotics for schizophrenia. $J$ Clin Psychopharmacol. 2006;26(6):632-637.

26. Citrome L, McEvoy JP, Todtenkopf MS, McDonnell D, Weiden PJ. A commentary on the efficacy of olanzapine for the treatment of schizophrenia: the past, present, and future. Neuropsychiatr Dis Treat. 2019;15:2559-2569.

27. Meftah AM, Deckler E, Citrome L, Kantrowitz JT. New discoveries for an old drug: a review of recent olanzapine research. Postgrad Med. 2020;132(1):80-90.

28. Yildiz A, Nikodem M, Vieta E, Correll CU, Baldessarini RJ. A network meta-analysis on comparative efficacy and all-cause discontinuation of antimanic treatments in acute bipolar mania. Psychol Med. 2015;45(2):299-317.

29. Cipriani A, Barbui C, Salanti G, et al. Comparative efficacy and acceptability of antimanic drugs in acute mania: a multiple-treatments meta-analysis. Lancet. 2011;378(9799):1306-1315.

30. Lindström L, Lindström E, Nilsson M, Höistad M. Maintenance therapy with second generation antipsychotics for bipolar disorder - a systematic review and meta-analysis. J Affect Disord. 2017;213:138-150.

31. Huhn M, Nikolakopoulou A, Schneider-Thoma J, et al. Comparative efficacy and tolerability of 32 oral antipsychotics for the acute treatment of adults with multi-episode schizophrenia: a systematic review and network meta-analysis. Lancet. 2019;394(10202):939-951.
32. Berkowitz RL, Patel U, Ni Q, Parks JJ, Docherty JP. The impact of the Clinical Antipsychotic Trials of Intervention Effectiveness (CATIE) on prescribing practices: an analysis of data from a large midwestern state. J Clin Psychiatry. 2012;73 (4):498-503.

33. Ketter TA, Haupt DW. Perceptions of weight gain and bipolar pharmacotherapy: results of a 2005 survey of physicians in clinical practice. Curr Med Res Opin. 2006;22(12):2345-2353.

34. Allison DB, Mentore JL, Heo M, et al. Antipsychotic-induced weight gain: a comprehensive research synthesis. Am J Psychiatry. 1999;156(11):1686-1696.

35. Tek C, Kucukgoncu S, Guloksuz S, Woods SW, Srihari VH, Annamalai A. Antipsychotic-induced weight gain in first-episode psychosis patients: a meta-analysis of differential effects of antipsychotic medications. Early Interv Psychiatry. 2016;10(3):193-202.

36. Simpson GM, Glick ID, Weiden PJ, Romano SJ, Siu CO. Randomized, controlled, double-blind multicenter comparison of the efficacy and tolerability of ziprasidone and olanzapine in acutely ill inpatients with schizophrenia or schizoaffective disorder. Am J Psychiatry. 2004;161(10):1837-1847.

37. Grootens KP, van Veelen NM, Peuskens J, et al. Ziprasidone vs olanzapine in recent-onset schizophrenia and schizoaffective disorder: results of an 8-week double-blind randomized controlled trial. Schizophr Bull. 2011;37(2):352-361.

38. Citrome L, Holt RI, Walker DJ, Hoffmann VP. Weight gain and changes in metabolic variables following olanzapine treatment in schizophrenia and bipolar disorder. Clin Drug Investig. 2011;31 (7):455-482.

39. Zhang Y, Wang Q, Reynolds GP, et al. Metabolic effects of 7 antipsychotics on patients with schizophrenia: a short-term, randomized, open-label, multicenter, pharmacologic trial. J Clin Psychiatry. 2020;81(3):19m12785.

40. Zyprexa [package insert]. Indianapolis, IN: Eli Lilly and Company; 2021.

41. Kinon BJ, Basson BR, Gilmore JA, Tollefson GD. Long-term olanzapine treatment: weight change and weight-related health factors in schizophrenia. J Clin Psychiatry. 2001;62(2):92-100.

42. Schoemaker J, Naber D, Vrijland P, Panagides J, Emsley R. Longterm assessment of asenapine vs. olanzapine in patients with schizophrenia or schizoaffective disorder. Pharmacopsychiatry. 2010;43(4):138-146

43. Bushe CJ, Slooff CJ, Haddad PM, Karagianis JL. Weight change from 3-year observational data: findings from the worldwide schizophrenia outpatient health outcomes database. J Clin Psychiatry. 2012;73(6):e749-e755.

44. Cerhan JR, Moore SC, Jacobs EJ, et al. A pooled analysis of waist circumference and mortality in 650,000 adults. Mayo Clin Proc. 2014;89(3):335-345.

45. Han TS, Lean ME. A clinical perspective of obesity, metabolic syndrome and cardiovascular disease. JRSM Cardiovasc Dis. 2016;5:2048004016633371.

46. Baker RA, Pikalov A, Tran QV, Kremenets T, Arani RB, Doraiswamy PM. Atypical antipsychotic drugs and diabetes mellitus in the US Food and Drug Administration Adverse Event database: a systematic Bayesian signal detection analysis. Psychopharmacol Bull. 2009;42(1):11-31.

47. Koro CE, Fedder DO, L'Italien GJ, et al. An assessment of the independent effects of olanzapine and risperidone exposure on the risk of hyperlipidemia in schizophrenic patients. Arch Gen Psychiatry. 2002;59(11):1021-1026.

48. Koro CE, Fedder DO, L'Italien GJ, et al. Assessment of independent effect of olanzapine and risperidone on risk of diabetes among patients with schizophrenia: population based nested case-control study. BMJ. 2002;325(7358):243. 
49. Moisan J, Gregoire JP, Gaudet M, Cooper D. Exploring the risk of diabetes mellitus and dyslipidemia among ambulatory users of atypical antipsychotics: a population-based comparison of risperidone and olanzapine. Pharmacoepidemiol Drug Saf. 2005;14(6):427-436.

50. Czyzyk TA, Nogueiras R, Lockwood JF, et al. kappa-Opioid receptors control the metabolic response to a high-energy diet in mice. FASEB j. 2010;24(4):1151-1159.

51. Czyzyk TA, Romero-Pico A, Pintar J, et al. Mice lacking deltaopioid receptors resist the development of diet-induced obesity. FASEB j. 2012;26(8):3483-3492.

52. Gallagher CJ, Gordon CJ, Langefeld CD, et al. Association of the mu-opioid receptor gene with type 2 diabetes mellitus in an African American population. Mol Genet Metab. 2006;87(1):54-60.

53. Haghighi A, Melka MG, Bernard M, et al. Opioid receptor mu 1 gene, fat intake and obesity in adolescence. Mol Psychiatry. 2014;19(1):63-68.

54. Raffan E, Dennis RJ, O'Donovan CJ, et al. A deletion in the canine POMC gene is associated with weight and appetite in obesityprone labrador retriever dogs. Cell Metab. 2016;23(5):893-900.

55. Tabarin A, Diz-Chaves Y, Carmona Mdel C, et al. Resistance to diet-induced obesity in mu-opioid receptor-deficient mice: evidence for a "thrifty gene". Diabetes. 2005;54(12):3510-3516.

56. Sehgal N, Smith HS, Manchikanti L. Peripherally acting opioids and clinical implications for pain control. Pain Phys. 2011;14(3):249-258.

57. Cheng KC, Asakawa A, Li YX, et al. Opioid $\mu$-receptors as new target for insulin resistance. Pharmacol Ther. 2013;139(3):334-340.

58. Mani AR, Moore KP. New insights into the role of endogenous opioids in the pathogenesis of gastrointestinal and liver disease. Gut. 2009;58(7):893-895.

59. Lybalvi [package insert]. Waltham, MA: Alkermes, Inc.; 2021.

60. Martin WF, Correll CU, Weiden PJ, et al. Mitigation of olanzapine-induced weight gain with samidorphan, an opioid antagonist: a randomized double-blind phase 2 study in patients with schizophrenia. Am J Psychiatry. 2019;176(6):457-467.

61. Potkin SG, Kunovac J, Silverman BL, et al. Efficacy and safety of a combination of olanzapine and samidorphan in adult patients with an acute exacerbation of schizophrenia: outcomes from the randomized, phase 3 ENLIGHTEN-1 study. J Clin Psychiatry. 2020;81(2):19m12769.

62. Correll CU, Newcomer JW, Silverman B, et al. Effects of olanzapine combined with samidorphan on weight gain in schizophrenia: a 24week phase 3 study. Am J Psychiatry. 2020;177(12):1168-1178.

63. Cunningham JI, Eyerman DJ, Todtenkopf MS, et al. Samidorphan mitigates olanzapine-induced weight gain and metabolic dysfunction in rats and nonhuman primates. J Psychopharmacol. 2019;33 (10):1303-1316.

64. Sun L, McDonnell D, Liu J, von Moltke L. Bioequivalence of olanzapine given in combination with samidorphan as a bilayer tablet (ALKS 3831) compared with olanzapine-alone tablets: results from a randomized, crossover relative bioavailability study. Clin Pharmacol Drug Dev. 2019;8(4):459-466.

65. Sun L, McDonnell D, Yu M, Kumar V, von Moltke L. A Phase I openlabel study to evaluate the effects of rifampin on the pharmacokinetics of olanzapine and samidorphan administered in combination in healthy human subjects. Clin Drug Investig. 2019;39(5):477-484.

66. Sun L, McDonnell D, von Moltke L. Pharmacokinetics and shortterm safety of ALKS 3831, a fixed-dose combination of olanzapine and samidorphan, in adult subjects with schizophrenia. Clin Ther. 2018;40(11):1845-1854.

67. Sun L, McDonnell D, Liu J, von Moltke L. Effect of food on the pharmacokinetics of a combination of olanzapine and samidorphan. Clin Pharmacol Drug Dev. 2019;8(4):503-510.

68. Sun L, Yagoda S, Yao B, Graham C, von Moltke L. Combination of olanzapine and samidorphan has no clinically significant effect on the pharmacokinetics of lithium or valproate. Clin Drug Investig. 2020;40(1):55-64.
69. Sun L, Yagoda S, Du Y, Von Moltke L. Effect of hepatic and renal impairment on the pharmacokinetics of olanzapine and samidorphan given in combination as a bilayer tablet. Drug Des Devel Ther. 2019;13:2941-2955.

70. Sun L, Yagoda S, Xue H, et al. Combination of olanzapine and samidorphan has no clinically relevant effects on ECG parameters, including the QTc interval: results from a phase 1 QT/ QTc study. Prog Neuropsychopharmacol Biol Psychiatry. 2020;100:109881.

71. Silverman BL, Martin W, Memisoglu A, DiPetrillo L, Correll CU, Kane JM. A randomized, double-blind, placebo-controlled proof of concept study to evaluate samidorphan in the prevention of olanzapine-induced weight gain in healthy volunteers. Schizophr Res. 2018;195:245-251.

72. Martin W, Graham C, Morrow L, et al. Insulin sensitivity and glucose metabolism of olanzapine and combination olanzapine and samidorphan: a phase 1 exploratory study in healthy volunteers [abstract 184]. CNS Spectr. 2020;25(2):316.

73. Brunette MF, Correll CU, O’Malley SS, et al. Olanzapine plus samidorphan (ALKS 3831) in schizophrenia and comorbid alcohol use disorder: a phase 2, randomized clinical trial. J Clin Psychiatry. 2020;81:2.

74. Yagoda S, Graham C, Simmons A, Arevalo C, Jiang Y, McDonnell D. Long-term safety and durability of effect with a combination of olanzapine and samidorphan in patients with schizophrenia: results from a 1-year open-label extension study. CNS Spectr. 2020.

75. Kahn RS, Silverman BL, DiPetrillo L, et al. A phase 3, multicenter study to assess the 1-year safety and tolerability of a combination of olanzapine and samidorphan in patients with schizophrenia: results from the ENLIGHTEN-2 long-term extension. Schizophr Res. 2021;232:45-53.

76. Wentland MP, Lou R, Lu Q, et al. Syntheses of novel high affinity ligands for opioid receptors. Bioorg Med Chem Lett. 2009;19 (8):2289-2294.

77. Bidlack JM, Knapp BI, Deaver DR, et al. In vitro pharmacological characterization of buprenorphine, samidorphan, and combinations being developed as an adjunctive treatment of major depressive disorder. J Pharmacol Exp Ther. 2018;367(2):267281.

78. Tan L, Gajipara N, Zhou Y, Namchuk M, Cunningham J. In vivo characterization of the opioid receptor binding profiles of samidorphan and naltrexone in rats: comparisons at clinically relevant concentrations [abstract T151]. Neuropsychopharmacology. 2020;45:250.

79. Turncliff R, DiPetrillo L, Silverman B, Ehrich E. Single- and multiple-dose pharmacokinetics of samidorphan, a novel opioid antagonist, in healthy volunteers. Clin Ther. 2015;37(2):338-348.

80. Nummenmaa L, Saanijoki T, Tuominen L, et al. $\mu$-opioid receptor system mediates reward processing in humans. Nat Commun. 2018;9(1):1500.

81. Cunningham JI, Dean RL, Todtenkopf MS, et al. Samidorphan attenuates drug-induced increases in extracellular dopamine concentrations and drug self-administration in rats [poster]. Presented at: Annual Meeting of the European College of Neuropsychopharmacology Congress; October 18-21. 2014; Berlin, Germany.

82. Baldo BA. Prefrontal cortical opioids and dysregulated motivation: a network hypothesis. Trends Neurosci. 2016;39(6):366-377.

83. Verspohl EJ, Berger U, Ammon HP. The significance of mu- and delta-receptors in rat pancreatic islets for the opioid-mediated insulin release. Biochim Biophys Acta. 1986;888(2):217-224.

84. Martin WF, Graham C, Morrow L, et al. Insulin sensitivity and glucose metabolism of olanzapine and combination olanzapine and samidorphan: a phase 1 exploratory study in healthy volunteers [poster]. Presented at: Annual Meeting of the American College of Neuropsychopharmacology; December 8-11, 2019; Orlando, FL. 
85. Wen T, Peng B, Pintar JE. The MOR-1 opioid receptor regulates glucose homeostasis by modulating insulin secretion. $\mathrm{Mol}$ Endocrinol. 2009;23(5):671-678.

86. Callaghan JT, Bergstrom RF, Ptak LR, Beasley CM. Olanzapine. Pharmacokinetic and pharmacodynamic profile. Clin Pharmacokinet. 1999;37(3):177-193.

87. Kumar V, Lu H, Hard M, von Moltke L. Characterization of the pharmacokinetics of samidorphan in healthy volunteers: absolute bioavailability and the effect of food and age. Drugs $R$ D. 2019;9 (3):277-287.

88. Kassahun K, Mattiuz E, Nyhart E Jr, et al. Disposition and biotransformation of the antipsychotic agent olanzapine in humans. Drug Metab Dispos. 1997;25(1):81-93.

89. Ring BJ, Catlow J, Lindsay TJ, et al. Identification of the human cytochromes $\mathrm{P} 450$ responsible for the in vitro formation of the major oxidative metabolites of the antipsychotic agent olanzapine. J Pharmacol Exp Ther. 1996;276(2):658-666.

90. Pathak S, Vince B, Kelsh D, et al. Abuse potential of samidorphan: a Phase I, oxycodone-, pentazocine-, naltrexone-, and placebo-controlled study. J Clin Pharmacol. 2019;59(2):218-228.

91. Drug Enforcement Administration. Schedules of controlled substances: removal of 6 $\beta$-naltrexol from control. Fed Reg. 2019;84 (162):43530-43536.

92. Latuda [package insert]. Marlborough, MA: Sunovion Pharmaceuticals Inc; 2018.

93. Rexulti [package insert]. Rockville, MD: Otsuka America Pharmaceutical, Inc; 2018.

94. Citrome L. Compelling or irrelevant? Using number needed to treat can help decide. Acta Psychiatr Scand. 2008;117(6):412-419.

95. Citrome L, Ketter TA. When does a difference make a difference? Interpretation of number needed to treat, number needed to harm, and likelihood to be helped or harmed. Int J Clin Pract. 2013;67 (5):407-411.

96. Kane JM, Skuban A, Hobart M, et al. Overview of short- and long-term tolerability and safety of brexpiprazole in patients with schizophrenia. Schizophr Res. 2016;174(1-3):93-98.

97. Forbes A, Hobart M, Ouyang J, Shi L, Pfister S, Hakala M. A long-term, open-label study to evaluate the safety and tolerability of brexpiprazole as maintenance treatment in adults with schizophrenia. Int J Neuropsychopharmacol. 2018;21(5):433-441.

98. Cutler AJ, Durgam S, Wang Y, et al. Evaluation of the long-term safety and tolerability of cariprazine in patients with schizophrenia: results from a 1-year open-label study. CNS Spectr. 2018;23 (1):39-50.

99. Nasrallah HA, Earley W, Cutler AJ, et al. The safety and tolerability of cariprazine in long-term treatment of schizophrenia: a post hoc pooled analysis. BMC Psychiatry. 2017;17(1):305.

100. Correll CU, Cucchiaro J, Silva R, Hsu J, Pikalov A, Loebel A. Long-term safety and effectiveness of lurasidone in schizophrenia: a 22-month, open-label extension study. CNS Spectr. 2016;21 (5):393-402.

101. Citrome L, O’Malley SS, McDonnell D, et al. Olanzapine plus samidorphan in subjects with schizophrenia and comorbid alcohol use disorder: rationale and design for a phase II, double-blind, randomized study. Innov Clin Neurosci. 2019;16(5-6):15-21.

102. Rickels MR, Perez EM, Peleckis AJ, et al. Contribution of parasympathetic muscarinic augmentation of insulin secretion to olanzapine-induced hyperinsulinemia. Am $J$ Physiol Endocrinol Metab. 2018;315(2):E250-e257.

103. Teff KL, Rickels MR, Grudziak J, Fuller C, Nguyen HL, Rickels $\mathrm{K}$. Antipsychotic-induced insulin resistance and postprandial hormonal dysregulation independent of weight gain or psychiatric disease. Diabetes. 2013;62(9):3232-3240.

104. Bazo-Alvarez JC, Morris TP, Carpenter JR, Hayes JF, Petersen I. Effects of long-term antipsychotics treatment on body weight: a population-based cohort study. J Psychopharmacol. 2020;34(1):79-85.
105. De Hert M, Peuskens B, van Winkel R, et al. Body weight and self-esteem in patients with schizophrenia evaluated with B-WISE. Schizophr Res. 2006;88(1-3):222-226.

106. Allison DB, Mackell JA, McDonnell DD. The impact of weight gain on quality of life among persons with schizophrenia. Psychiatr Serv. 2003;54(4):565-567.

107. Weiden PJ, Kozma C, Grogg A, Locklear J. Partial compliance and risk of rehospitalization among California Medicaid patients with schizophrenia. Psychiatr Serv. 2004;55(8):886-891.

108. Bessonova L, Velligan DI, Weiden PJ, et al. Antipsychotic treatment experiences of people with bipolar I disorder: patient perspectives from an online survey. BMC Psychiatry. 2020;20 (1):354.

109. Kawachi I. Physical and psychological consequences of weight gain. J Clin Psychiatry. 1999;60(Suppl 21):5-9.

110. Mitchell AJ, Vancampfort D, Sweers K, van Winkel R, Yu W, De Hert M. Prevalence of metabolic syndrome and metabolic abnormalities in schizophrenia and related disorders-a systematic review and meta-analysis. Schizophr Bull. 2013;39(2):306-318.

111. De Hert M, Dekker JM, Wood D, Kahl KG, Holt RI, Moller HJ. Cardiovascular disease and diabetes in people with severe mental illness position statement from the European Psychiatric Association (EPA), supported by the European Association for the Study of Diabetes (EASD) and the European Society of Cardiology (ESC). Eur Psychiatry. 2009;24(6):412-424.

112. Hales CM, Carroll MD, Fryar CD, Ogden CL. Prevalence of obesity and severe obesity among adults: united States, 2017-2018. NCHS Data Brief. 2020;(360):1-8.

113. Annamalai A, Kosir U, Tek C. Prevalence of obesity and diabetes in patients with schizophrenia. World J Diabetes. 2017;8(8):390396.

114. Strassnig M, Kotov R, Cornaccio D, Fochtmann L, Harvey PD, Bromet EJ. Twenty-year progression of body mass index in a county-wide cohort of people with schizophrenia and bipolar disorder identified at their first episode of psychosis. Bipolar Disord. 2017;19(5):336-343.

115. Newcomer JW. Metabolic syndrome and mental illness. Am J Manag Care. 2007;13(7 Suppl):S170-S177.

116. Papanastasiou E. The prevalence and mechanisms of metabolic syndrome in schizophrenia: a review. Ther Adv Psychopharmacol. 2013;3(1):33-51.

117. Correll CU, Ng-Mak DS, Stafkey-Mailey D, Farrelly E, Rajagopalan K, Loebel A. Cardiometabolic comorbidities, readmission, and costs in schizophrenia and bipolar disorder: a realworld analysis. Ann Gen Psychiatry. 2017;16:9.

118. Mizuno Y, Suzuki T, Nakagawa A, et al. Pharmacological strategies to counteract antipsychotic-induced weight gain and metabolic adverse effects in schizophrenia: a systematic review and meta-analysis. Schizophr Bull. 2014;40(6):1385-1403.

119. Maayan L, Vakhrusheva J, Correll CU. Effectiveness of medications used to attenuate antipsychotic-related weight gain and metabolic abnormalities: a systematic review and meta-analysis. Neuropsychopharmacology. 2010;35(7):1520-1530.

120. Baptista T, Martinez J, Lacruz A, et al. Metformin for prevention of weight gain and insulin resistance with olanzapine: a doubleblind placebo-controlled trial. Can J Psychiatry. 2006;51(3):192196.

121. Baptista T, Rangel N, Fernandez V, et al. Metformin as an adjunctive treatment to control body weight and metabolic dysfunction during olanzapine administration: a multicentric, double-blind, placebo-controlled trial. Schizophr Res. 2007;93(1-3):99-108.

122. Arman S, Sadramely MR, Nadi M, Koleini N. A randomized, double-blind, placebo-controlled trial of metformin treatment for weight gain associated with initiation of risperidone in children and adolescents. Saudi Med J. 2008;29(8):1130-1134. 
123. Wu RR, Zhao JP, Guo XF, et al. Metformin addition attenuates olanzapine-induced weight gain in drug-naive first-episode schizophrenia patients: a double-blind, placebo-controlled study. Am J Psychiatry. 2008;165(3):352-358.

124. Cooper SJ, Reynolds GP, Barnes T, et al. BAP guidelines on the management of weight gain, metabolic disturbances and cardiovascular risk associated with psychosis and antipsychotic drug treatment. J Psychopharmacol. 2016;30(8):717-748.

125. Bushe CJ, Slooff CJ, Haddad PM, Karagianis JL. Weight change by baseline BMI from three-year observational data: findings from the Worldwide Schizophrenia Outpatient Health Outcomes Database. J Psychopharmacol. 2013;27(4):358-365.

126. Lee SY, Park MH, Patkar AA, Pae CU. A retrospective comparison of BMI changes and the potential risk factors among schizophrenic inpatients treated with aripiprazole, olanzapine, quetiapine or risperidone. Prog Neuropsychopharmacol Biol Psychiatry. 2011;35(2):490-496.
127. Fleischhacker WW, Siu CO, Boden R, Pappadopulos E, Karayal ON, Kahn RS. Metabolic risk factors in first-episode schizophrenia: baseline prevalence and course analysed from the European First-Episode Schizophrenia Trial. Int J Neuropsychopharmacol. 2013;16(5):987-995.

128. McEvoy JP, Lieberman JA, Perkins DO, et al. Efficacy and tolerability of olanzapine, quetiapine, and risperidone in the treatment of early psychosis: a randomized, double-blind 52-week comparison. Am J Psychiatry. 2007;164(7):1050-1060.

\section{Publish your work in this journal}

Neuropsychiatric Disease and Treatment is an international, peerreviewed journal of clinical therapeutics and pharmacology focusing on concise rapid reporting of clinical or pre-clinical studies on a range of neuropsychiatric and neurological disorders. This journal is indexed on PubMed Central, the 'PsycINFO' database and CAS, and is the official journal of The International Neuropsychiatric Association (INA). The manuscript management system is completely online and includes a very quick and fair peer-review system, which is all easy to use. Visit http://www.dovepress.com/testimonials.php to read real quotes from published authors. 